Article

\title{
Green Supplier Selection Criteria: From a Literature Review to a Comprehensive Knowledge Base
}

\author{
Agnieszka Konys \\ Faculty of Computer Science and Information Technology, West-Pomeranian University of Technology in \\ Szczecin, Ul. Żołnierska 49, 71-210 Szczecin, Poland; akonys@zut.edu.pl
}

Received: 2 July 2019; Accepted: 1 August 2019; Published: 3 August 2019

\begin{abstract}
The supplier selection problem is one of the most important competitive challenges used by modern enterprises. Due to the fact that companies have to improve their practices in the management of a green supply chain that aims to respect green practices and technologies to increase sustainability, selecting the optimal green supplier is a challenging multi-dimensional problem. While most of the research has focused on the development and improvement of new methods, relatively limited attention has been paid to the identifying sets of criteria and capturing the domain knowledge. This issue is significant because a correctly identified set of criteria plays a vital role in supporting the decision-making process. The approach presented creates a gap between classical assumption of decision making and knowledge-based problem structuring. The current paper presents a methodological and practical background for capturing and handling knowledge about green supplier selection criteria, supported by a formal guideline for their appropriate acquisition. In addressing this research challenge, the aims of this paper are twofold: providing meta-analysis to reveal a collection of key data supported by a formal and trustworthy bibliometric analysis, and capturing knowledge in one place in the form of ontology for enabling selection and evaluation criteria of green suppliers is proposed. The proposed ontology is available for public use.
\end{abstract}

Keywords: green supplier selection; ontology; criteria for green supplier selection and evaluation; knowledge capturing and handling

\section{Introduction}

Green supplier selection is gaining increasing interest among researchers and practitioners due to the growing awareness of environmental protection and its long-term effects on business and marketing issues. In today's business world, green supplier selection has a critical effect on the competitiveness of the entire supply chain network [1-5]. Presently, companies need to consider and include so-called 'green strategies' in order to prevent the negative impact of the industrial processes and also to optimally manage the physical and information flows exchanged between all actors in a supply chain [6]. On the other hand, a scattered model of conducting business and global competition force companies to consider the necessity for developing activities of proper selection and evaluation of beneficial supply chain partnerships. Supply chains are basically a source of competitive advantage, and require the collaboration and synchronisation of many companies to operate the common objectives of effectively and efficiently satisfying customers' requirements [7]. As a result, selecting the optimal green supplier is crucial for green supply chain management, which is a challenging multi-dimensional problem. Meanwhile, it may influence directly and indirectly the consequences of worse decision making processes [8]. A suitable green suppliers' recommendation forms the basis for a successful building of a competitive advantage of a company. The current practice for the selection of green suppliers arises from a company's inclination to respond to any existing trends in environmental 
issues related to business management and processes. In particular, the discovery and selection of knowledgeable suppliers has become a fundamental issue for global supply chain management.

The choice of valuable suppliers ought to be focused on that type of partners that aim to respect green practices and technologies to increase sustainability. The assessment of the selection criteria does not only encompass the offered services and material quality, but also the supplier's opportunities for sustainable development, by adding individual green orientation to models of entrepreneurial intention to increase their explanatory power. Thus, a crucial key is to further establish the green policy of the company, especially with regard to supply chain management. There are many recent studies which focus on the green supplier selection issues, and there are also different approaches based on various methods, statistical models and artificial intelligence based models [9], data envelopment analysis [8], multi-criteria decision models/approaches [10], and cluster analysis, case-based reasoning systems [5]. With the large number of works oriented towards the development of methodological background in the green supplier selection process, little attention is paid to identifying and selecting the proper set of assessment criteria. Thus, the construction of models is based only on the knowledge of the experts/decision makers. [11-14]. It should be pointed that this process is very significant because a properly selected set of criteria determines the quality and correctness of the evaluation model developed each time [11-14]. When considering the paradigms of the decision support process (Figure 1), it is easy to see the possible complementing of the existing research gap at the stage of the model's structuring phase.

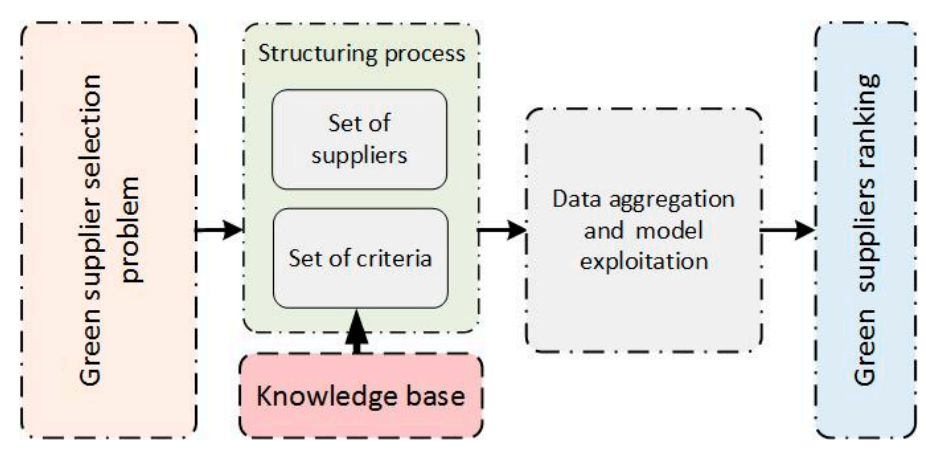

Figure 1. Conceptual framework for green supplier selection.

In particular, it is postulated to extend the analyst/decision maker's knowledge in the process of identifying the conditional and decisional attributes of the model with reference recommendations of the green-oriented supplier selection criteria sets. Thus, the expected effect of the following research is to build the methodological and practical foundations for generating recommendations in the area with the use of collected knowledge.

Meanwhile, a number of scientific papers about green supplier selection have increased significantly. Even though there are many studies in the literature about green supplier selection, knowledge about the factors and their interrelationships in facilitating green supplier selection in companies is scattered. That means, we need to find a new general way to systematically collect and handle knowledge about selection and evaluation criteria of suppliers. In the dynamic alliance/cooperation environment, different companies put some effort into ensuring greater supply chain collaboration with upstream and downstream partners and therefore should leverage the resources and knowledge of suppliers and valued customers as well, capitalising on prospects for learning and knowledge formation [11,12]. In addressing this research challenge, capturing knowledge in one place in the form of an ontology for enabling selection and evaluation criteria of suppliers is proposed. As a result, the motivation of the current research was:

- to bring a gap between classical assumption of decision making and knowledge-based problem structuring; 
- to obtain a high accuracy of and quality of collected papers for data aggregation about criteria determining green-oriented supplier selection;

- to address the lack of knowledge issue in the scattered criteria determining green-oriented supplier selection.

To meet this research aim, as well as to discover implicit, incompatible and inconsistent conceptual forms and to effectively handle scattered knowledge about green suppliers for collaborative companies, an implementation of knowledge management in facilitating green supplier selection is introduced. Ontological engineering attempts to define abstract knowledge for certain domains in terms of elements such as entity, property and relationship using systematic methods and processes and then to transform such knowledge into explicit, formal specifications. The main advantage of the ontology-based approach is to share information about existing literature sources and applied criteria for supplier selection and evaluation for enabling its semantics-driven knowledge processing, although the proposed ontology needs to be constantly improved in future practice and enriched by new knowledge. Thus, the objectives of this paper are twofold: one is to summarize the literature on green-oriented supplier selection from nominated articles published during 2007 to 2019, particularly on supplier selection and evaluation criteria. A high quality of collected papers is proved as in the referenced top listed journals and supported by a formal and trustworthiness bibliometric analysis. Second, based on that, the ontology-based approach synthetizing the analyzed selection and evaluation criteria of suppliers are proposed. The proposed ontology-based model is demonstrated by an empirical example of using competency questions to confirm its correctness and effectiveness. The Preferred Reporting Items for Systematic Reviews and Meta-Analyses (PRISMA) methodology [13] was used to provide appropriateness of data collected.

Due to the fact that the aims of this research are heterogeneous, the detailed justification should be provided. As was mentioned above, the research gap covered both bibliometric analysis and knowledge handling about green supplier selection criteria which resulted in the interdisciplinary nature of the research conducted. The Table 1 presents the main statements and summarizes the outcomes of research conducted.

Table 1. The main statements and outcomes of research.

\begin{tabular}{|c|c|c|}
\hline Research Questions & Motivations & Outcomes \\
\hline $\begin{array}{l}\text { RQ1: How to select the } \\
\text { optimal green supplier }\end{array}$ & $\begin{array}{l}\text { Focusing on development and } \\
\text { improvement of new methods by most of } \\
\text { the research. } \\
\text { Limited attention has been paid to the } \\
\text { identifying sets of criteria and capturing of } \\
\text { the domain knowledge. } \\
\text { A gap between classical assumption of } \\
\text { decision making and knowledge-based } \\
\text { problem structuring. }\end{array}$ & $\begin{array}{l}\text { Presenting a methodological and practical } \\
\text { background for capturing and handling } \\
\text { knowledge about green supplier selection } \\
\text { criteria, supported by a formal guideline for } \\
\text { their appropriate acquisition. }\end{array}$ \\
\hline $\begin{array}{l}\text { RQ2: What are most } \\
\text { pertinent criteria } \\
\text { determining green supplier } \\
\text { selection? }\end{array}$ & $\begin{array}{l}\text { Providing a macroscopic overview of } \\
\text { global research trends of green supplier } \\
\text { selection based on a bibliometric analysis. }\end{array}$ & $\begin{array}{l}\text { Providing meta-analysis to reveal a collection of } \\
\text { key data supported by a formal and } \\
\text { trustworthiness bibliometric analysis. }\end{array}$ \\
\hline $\begin{array}{l}\text { RQ2.1: What are the most } \\
\text { influential keywords } \\
\text { determining green supplier } \\
\text { selection? }\end{array}$ & $\begin{array}{l}\text { An attempt to extend prior research by } \\
\text { yielding heterogeneous informative } \\
\text { overview within the past twelve-year } \\
\text { period with a focus on keyword occurrence } \\
\text { analysis. }\end{array}$ & $\begin{array}{l}\text { Providing an overview of the development of } \\
\text { the field of green supplier selection and } \\
\text { analysis of collected data. }\end{array}$ \\
\hline $\begin{array}{l}\text { RQ2.2: What are the } \\
\text { correlations, properties and } \\
\text { inclusion scheme among the } \\
\text { criteria indicated by cluster } \\
\text { analysis? }\end{array}$ & $\begin{array}{l}\text { Visible lack of the classification and } \\
\text { systematization of used criteria. } \\
\text { Visible lack of a broad and multifaceted } \\
\text { view of criteria determining green supplier } \\
\text { selection in the form of roadmap. } \\
\text { Highlighting the most prominent fields } \\
\text { based on the collection of investigated } \\
\text { keywords/criteria. }\end{array}$ & $\begin{array}{l}\text { Providing a new deep insight for the } \\
\text { underpinning building blocks to allow properly } \\
\text { adapting within each criterion and to show } \\
\text { how these criteria correlate with each other. } \\
\text { A descriptive summary of existing correlations } \\
\text { and a clustering analysis, and also } \\
\text { multidimensional scaling of properties between } \\
\text { the criteria. }\end{array}$ \\
\hline
\end{tabular}


Table 1. Cont.

\begin{tabular}{|c|c|c|}
\hline Research Questions & Motivations & Outcomes \\
\hline $\begin{array}{l}\text { RQ3: How to gather } \\
\text { knowledge about the } \\
\text { criteria for choosing a green } \\
\text { supplier and manage it } \\
\text { effectively }\end{array}$ & $\begin{array}{l}\text { A visible lack of complete knowledge base } \\
\text { about green supplier selection criteria. } \\
\text { A visible lack of publicly available } \\
\text { knowledge about green supplier selection } \\
\text { criteria, collected in a one place. }\end{array}$ & $\begin{array}{l}\text { Capturing knowledge in one place in the form } \\
\text { of ontology for enabling selection and } \\
\text { evaluation criteria of green suppliers at the } \\
\text { same time providing interoperability of } \\
\text { collected knowledge. }\end{array}$ \\
\hline $\begin{array}{l}\text { RQ3.1: How to prepare } \\
\text { relatively trustworthiness } \\
\text { set of criteria }\end{array}$ & $\begin{array}{l}\text { A need for comprehensive elaboration of } \\
\text { available criteria determining green } \\
\text { supplier selection. }\end{array}$ & $\begin{array}{l}\text { Condensing large amounts of bibliographic } \\
\text { information and revising and elaborating of } \\
\text { harvested data by affixture of rules and } \\
\text { limitations. } \\
\text { Analyzing and cleaning the data to create } \\
\text { relevant and comprehensive information in the } \\
\text { form of a set of clusters with assigned criteria. }\end{array}$ \\
\hline $\begin{array}{l}\text { RQ3.2: How to ensure } \\
\text { access to the valuable } \\
\text { knowledge of } \\
\text { green-oriented suppliers } \\
\text { and how to effectively } \\
\text { capture the learning } \\
\text { knowledge }\end{array}$ & $\begin{array}{l}\text { A visible lack of advanced technological } \\
\text { solutions to acquire and share knowledge } \\
\text { to successfully support supply chains. }\end{array}$ & $\begin{array}{l}\text { Knowledge sharing and best practice between } \\
\text { partners to accomplish collective goals. } \\
\text { Independent knowledge about criteria for } \\
\text { green-oriented supplier selection proved by } \\
\text { scientific analysis of literature. } \\
\text { Obtained knowledge can be incorporated into } \\
\text { any database, knowledge base or information } \\
\text { system holding knowledge associated to green } \\
\text { or sustainability domain. } \\
\text { Possibility of a machine-readable access and } \\
\text { handling semantic data can improve the } \\
\text { searching capacity and knowledge sharing of } \\
\text { the proposed ontology. } \\
\text { The proposed ontology is featured by } \\
\text { multi-usage, reusing, and also knowledge } \\
\text { sharing and dissemination. } \\
\text { The possible extension of the current collection } \\
\text { of criteria and expansion of this ontology of } \\
\text { other domains, closely related with green and } \\
\text { sustainability. }\end{array}$ \\
\hline
\end{tabular}

The choice of the mean of knowledge conceptualization in the form of ontology is motivated by its wide practical applicability. The scientific knowledge is focused on the human [14,15]. Often, the collected documents (e.g., expert knowledge sources or scientific papers) do not contain the context and they are understood by humans (in a textual or graphical form). However, machines are not able to process these documents. At present, information technology (IT) techniques allow to share not only effective collection and processing of the data and information, but also effective knowledge management: its storage and reuse [16-19]. Thus, it is needed to build autonomous concept classification systems (e.g., knowledge bases) [20,21]. In many scientific studies, the systems to knowledge collection in the human- and machine-understandable form (in other words, ontologies) are introduced as the best way of knowledge storage, and it is the goal of the research itself [22-24].

Ontologies in computer science represent multi-tasking artefacts $[18,20]$ that create a framework for such a view of objects and processes in a given field, in which every emerging concept has a precisely defined meaning [14,25]. The aim of development of ontology is analyzing and organizing our knowledge about the elements of a given field and the ways of expressing it [16,26,27]. From a practical point of view, ontology construction allows making all assumptions underlying our way of capturing the modelled field (including those more or less hidden) [16,24], a multifaceted representation of dependencies between different fragments of the presented slice of reality and defining criteria allowing to unambiguously classify data from a given field [24,28]. It may mean an advantage in the form of creating a certain interdisciplinary basis for communication between experts $[23,29,30]$ or just reveal not always coherent ways to deal with certain issues $[15,20]$. In addition, due to its formal structure, ontology allows systematic inference about what belongs to its domain $[14,18]$ - this means that we can not only create a model of a given problem, project, process, enterprise, but also provide it with data from information systems [22]. From a formal point of view, concepts and relationships 
included in an ontology may be formally processed by intelligent agents [22,26]. As a consequence, the description of a given field of knowledge using an ontology can handle as a basis for inferring the properties of the described ontology [27]. Therefore, an ontology is more than a close representation of our knowledge, because it can provide a flexible platform for building or integrating information and elements of information systems based on them [14]. By building ontologies we gain not only a deep insight into the basics of the modelled domain, but we can also determine the semantic space of the concepts appearing in it [20]. This means that we define what and how it can be said meaningful, how concepts can connect with each other, what types of statements can appear in a given model with regard to its individual elements [22,24]. It causes that ontologies help exchange information into well-founded knowledge [17,31]. It is worth emphasizing that the value of ontologies is appreciated by engineers and researches mostly in medicine (e.g., gene ontologies) [32] and, likewise, social and human researchers (e.g., digital ontological repositories of domain scientific papers) [18,26,33-36].

The paper is structured as follows: Section 2 presents literature review, including state-of-the-art both of the suppliers' selection approaches and of knowledge management approaches for supplier selection, followed by the definition of the research gap. In Section 3 a research procedure and its formal foundations is provided as well as a formal meta-analysis. The obtained classification of selected criteria followed by the main assumptions of knowledge systematization for green-oriented supplier selection criteria is also provided. Section 4 presents the approach in the form of an ontology for green-oriented supplier selection, proved by its exemplary validation using competency questions. The article concludes with a discussion of the results achieved and areas of further research.

\section{Literature Review}

\subsection{State-of-the-Art of the Suppliers' Selection Approaches}

The investigated literature provides some distinctive terms that reflect the conception of green supply chain management, especially including sustainable supply network management [37,38]; supply and demand sustainability in corporate social responsibility networks [37,39]; supply chain environmental management [40]; green purchasing [41] and procurement [42]; environmental purchasing [43,44]; green logistics and environmental logistics [45]; and sustainable supply chains $[46,47]$. The current state-of-the-art of the literature of suppliers' selection approaches is presented to outline some of its main directions. Previous works started from general approaches dedicated to managing supply chains. This research concentrated on initial aspects of various industrial ecology principles [48] with concepts like life-cycle assessment. This advanced the industrial eco-systems philosophy [49] and approved the supply chain concept as a strategic competitive weapon [50]. The measurement of profit impact and supply risk in the form of a matrix was proposed by [51], wherein further elaboration and analysis of the categories of items were shown by [52]. To continue, the further refinement of designing and managing supply chains were inspired by issues in green manufacturing and product recovery [53], production planning and control for remanufacturing [54], logistics network design [55,56] and interactions among various stakeholders on integrated green supply chain management [53] as well as suppliers' performance measurements [57].

From the perspective of theoretical approaches focused on supplier selection, Rezaei and Ortt [58] classified the extant works in three groups: process, portfolio and involvement methods [59]. In other work Rezaei and Ortt [60] applied fuzzy logic for supplier segmentation. The conceptual manner of the approaches to supplier categorization using questionnaires and case studies was demonstrated by Day, Magnan, and Moeller [61] in their work. The application of generic algorithms to solve the supplier' selection problem was proposed by Ip et al. [62]. In this approach the main aim was to represent the risk preference of a customer. Likewise, to discover and select suppliers effectively, customers have to weigh up multiple perspectives, and for this reason, according to [63], some existing approaches are not appropriate for building a long-term supply chain, but only for a single trading of specific products. 
The statement that the supplier evaluation problem has a multiple criteria nature was posed in the works $[59,64]$. Similarly, the segmentation of decision making methodologies for green supplier selection into individual and integrated methodology approach was investigated by Govindan et al. [65]. The approximate division of decision making techniques of supplier selection highlights such techniques as multi-criteria decision making, mathematical programming and artificial intelligence [66]. Developing this trend, some research exactly referred to multi criteria decision analysis methods, for example Lee and Drake [67], who applied portfolio models by using AHP to obtain weights of criteria, and direct rating to obtain the score of items, or Huang and Mak [68] have developed three indices to express preferences of satisfaction degree, risk and flexible rate. To measure which supplier solution is more similar to the ideal preference of a customer, the technique for order performance by similarity to ideal solution (TOPSIS) was adapted by Opricovic and Tseng [69]. Furthermore, a new method, the best worst method (BWM) was used in order to obtain criteria weights for supplier development [70]. To find influential factors in selecting suppliers, Chang et al. [71] used the Decision Making Trial and Evaluation Laboratory (DEMATEL) method, emphasizing the most significant ones.

The reviewed literature also provided a number of supplier discovery methods, ranging from classic information retrieval methods for text comparison, to more sophisticated semantic-matching-based ones using ontologies [34,72-74]. The literature analysis showed that some examples utilized semantic web-based systems for supplier selection and discovery [75], an internet-based prototype to find and select suppliers [76] or ontologies used for modelling customer's requirements [77,78], where ontology-based methodology was adapted to identify and select the appropriate evaluation criteria for understanding buyer's requirements [77]. Also supplier selection methods can divide to single and combined models [79]. Single models encompass mathematics approaches (e.g., AHP, linear programming, multi-objective programming, goal programming and also simulations and heuristics), single models such as cluster analysis, multiple regression or discriminant analysis, and artificial intelligence approaches including as an example neural networks, fuzzy set theory and software agents. Recently, because of high flexibility in combined models, they are developed more [80]. They refer to conjunctions of various single models, for example AHP with goal programming or AHP with fuzzy set theory [64].

In addition, to assess all approved suppliers, the set of criteria distinguishing them is expected. In earlier work, there were some attempts to construct a finite set of criteria in various supplier selection problems. Recent studies conducted by Dickson [81] and continued by Weber et al. [82] provided 23 distinct criteria derived from published articles between 1966 and 1990. The most influential ones were: product quality, on-time delivery, performance history of supplier and warranties and claimed policies [2]. It was continued and extended by adding 13 more criteria in the later bibliometric analysis of articles published between 1990 and 2001 by Cheraghi et al. [83]. The further refinement of this work was pursued by Thiruchelvam and Tookey [84], who reviewed supplier selection studies and, based on this, comprised the selection criteria between two periods of 1966-2001 and 2001-2010. To continue this effort, I. E. Nielsen et al. [2] systematized this knowledge about 90 criteria on base of reviewing chapters, wherein a very large set of criteria were utilized in various works (e.g., [65]). In-depth analysis of literature pointed out that sometimes authors used the same criteria but in a different statement. It may cause a kind of dispersion in criteria, and consequently makes a researcher ambiguous to select criteria. According to [2], a visible lack of concordant studies about basic green criteria caused widespread number of green criteria in each study. Nonetheless, a rapid development of the market as well as an increasing number of suppliers over the years forces changes in considered criteria. Therefore, the inception of new criteria is essential to qualify relevant suppliers. Under the current rapid green supply chain management development, reliability and flexibility of each supplier are considered as key contributing factors. Reviewing literature pointed that most of supplier selection criteria are selected based on relevancy [65,82], which is important but not adequate, because variation of products, industries and etc. will affect some criteria. Reviewing literature pointed that most of supplier selection criteria are selected based on relevancy $[65,82]$, however, variation of 
products, industries and technologies may affect some criteria. Hence, the differentiate sets of criteria are needed to ensure a more tangible supplier selection process and lead to obtaining high accuracy results. As noted before, a systematic approach for selecting suppliers is required as it can help to build closeness and a long-term relationship between partners. But the core problem is how to select a supplier to better meet the real preference of a customer [85]. Working with the best approved suppliers should be tested and proved over time by using a systematic and robust procedure to ensure the relevant personalization of a supplier' profile preferences.

There is an increasing need for feedback to the suppliers on their performance. Even though there are some guidelines and literature studies about basic green criteria, measuring the suppliers' capability to meet these requirements seems to be crucial for a successful green supply chain. Related to this, Luo et al. [86] note that only suppliers that improve continuously (i.e., always innovative) can sustain their competitive advantage. To summarize, reviewing literature showed that most of supplier selection ventures are influenced by individual skills of the supply chain partners [87], trust among the supply chain partners [88], leadership skills [89], and also managing and sharing knowledge between the workforce [90].

\subsection{State-of-the-Art of Knowledge Management Approaches for Supplier Selection}

Knowledge can be defined as a product of learning, which enables achieving competitive advantage by relevant actions, and making valuable decisions [23,91]. In the era of the knowledge economy, the building competitive advantage by green-oriented companies requires the abilities to acquire knowledge of the supplier' performance to meet the customer needs. Thus, sharing knowledge is essential to establish trust and building the closeness and long-term relationship between partners and suppliers [90]. However, the need to export and import the information between various sources may aggravate the problem, causing the process to be susceptible to human errors [92]. The effective abilities to acquire, manage and share knowledge may help solving problems and preventing these mistakes [93]. But companies need to have the ability to locate and access the required knowledge about green suppliers when it is needed [85]. Thus, timely access to knowledge can be critical for further decisions [94]. From a business perspective, knowledge management allows companies to collect previous and current information of green-oriented suppliers and their lessons learned from the collaborators [95], and consequently it helps making better decisions.

The access to knowledge can be from internal and external sources [96]. Internal knowledge is produced by companies, whereas external knowledge is derived from external companies. Skillful knowledge management (KM) should encompass both of the knowledge types [33]. Access to internal and external knowledge simultaneously is critical for proper identification of green-oriented suppliers and sustainable opportunities related to the information they currently possess. However, access to knowledge of the suppliers can be even more crucial to the companies that collaborate with a large number of partners [91]. With active knowledge-sharing, suppliers, who form an essential part of the supply chain, are valuable sources of knowledge and innovation [97]. According to [91], another problem concerns limited access to knowledge, especially to external knowledge sources possessed by suppliers. Therefore, ensuring access to the knowledge of green-oriented suppliers can be decisive to the partners, so this knowledge should be captured continuously. However, just the proper codification of knowledge and its unlimited access can help improve knowledge transfer between companies and their partners [98]. To solve this problem, a crucial issue is how to motivate suppliers to contribute knowledge captured by them and how to effectively capture the learning knowledge. As knowledge is often one of the main elements to advance sustainable competitiveness, the companies should ensure knowledge-sharing and best practice between partners [30] to accomplish collective goals [99]. It is worth noting that a suitable knowledge management tool is another key enabler for successful collaboration between geographically separate companies. The companies that have the capability to acquire and share knowledge are the most likely to automate their supply chains successfully through advanced technological solutions [100]. 
An increasing need for green-oriented supply chain collaboration at various levels can be facilitated by ensuring effective KM mechanisms to supplement each other's strengths and shape their association and supply chain strategies [101]. Revising literature showed that there were some attempts to implement knowledge-based solutions. For example, the Web-Based Sub-Contractor Evaluation System (WEBSES) was proposed by Arslan et al. [102] to ensure sub-contractors were evaluated online based on a set of combined criteria. A conceptual KM model was introduced by Desai and Rai [103] to extract explicit knowledge from the databases owned by the customer company and store them in a knowledge base. Another work developed by Rodríguez-Enríquez et al. [104] introduced a new software architecture called Simple Knowledge Organization Chain Management (SKOSCM) to analyse the dataflow among the partners and suppliers. The compound approach exploiting AHP and the fuzzy matrix integrated evaluation model allows assessing the performance of supply chain knowledge collaboration in various aspects [105]. Extant literature research addressed other knowledge-based solutions, presenting for example KM systems developed to enable the partners companies to provide inputs and share their knowledge with the suppliers, with the aim to help improve the suppliers' performance (e.g., $[36,85,106]$. An attempt to revising existing literature on knowledge management and supply chain management was taken by $[89,107]$. The aim was to determine the most influential factors that define KM in enabling green-oriented supply chain collaboration. The proposed model was composed of 24 factors based on the strategic, managerial, organisational, operational, technological, human-socio, financial and environmental dimensions.

Previous research was conducted by Uschold et al. [24] and Fox and Gruninger [17], who extended the ontology to be used in the dynamic alliance environment in enterprise project and TOronto Virtual Enterprise (TOVE) project. Previously, an ontology has also been extended in knowledge management in dynamic alliance using semantic web services [108]. The conception of dynamic alliances was also taken Chen [79], who presented a novel approach for knowledge access control and sharing in a dynamic alliance. Maamar et al. in [109] proposed a framework to support partners' interactions during commercial activities through mobiles. Final effect is a social network for collaboration and recommendation. Another recommender system was developed by [110] to select a suitable but also trustworthy supplier among the huge number of available ones, exploiting the decision tree technique for suppliers' classification. In work the authors propose a multi-agent system platform with the integration of the ontology concept into multi agent systems. The ontology-based framework aims to select the suitable collaborators. However suppliers are selected relying on several criteria such as price, quantity, quality, lead time but also environmental factors like environmental management, green image, green product and pollution control [91]. Furthermore, Dhaouadi et al. [26] outlined the multi agent system conception for the supply chain, where the system is designed to automatically recommend suitable suppliers. This recommender system operates under a heterogeneous environment from business and social perspectives, and underlines the presence of customers and suppliers from very different contexts [26]. Further development of ontology-based systems was elaborated by Lee et al. [75]. The authors proposed a semantic web-based supplier discovery system for building a long-term supply chain. The ontology was used to represent the supplier's capability information and the customer's requirements. Based on the reasoning mechanisms, a supplier's potential capability is computed and, in the aftermath of this, customer's requirements are semantically matched with supplier's capability based on a similarity calculation.

On basis of the literature analysis, a number of supplier selection approaches exploiting ontology-based solutions and KM have been introduced. In general, the aim of these solutions is to help to resolve semantic issues between suppliers and partners. Meanwhile, to be more open to the companies, supplier selection systems need to be developed based on current practice and techniques enhancing knowledge-sharing. Oftentimes, the proposed solutions are only for the one-off selection of the suppliers for each of the venture. A missing point is the repetitiveness of this selection based on gained experience. Therefore, the selection process of the most suitable supplier for the right venture needs to be integrated and encapsulated into one system. 


\section{Materials and Methods}

\subsection{Methodological Overview}

In this section, the description of conducted experiments related to searching documents is provided. To meet the aims of the study, the procedures of systematic literature reviews and bibliometric techniques and tools were adopted. The conceptual steps are shown in Figure 2. The research procedure is composed of the three parts connected with each other. The first of them is responsible for searching documents. Typically, this process is carried out based on employing one of four widely popular databases which include Web of Knowledge, Scopus, Google Scholar and PubMed. In this paper, the Scopus database was used to retrieve documents related to supplier selection and evaluation criteria. To confirm the usage of Scopus database, it is deemed to grant the most flexible overview of the global research productivity in all domains of science. To ensure a lack of bias and trustworthiness of this process, the PRISMA methodology was employed [13]. It is well-known and one of the most popular methodology for conducting a systematic literature review. What is more, it is the largest database which indexes the largest number of journals than other scientific research databases. However this process needs the manual screening of the most relevant sources. At the end of this process, a set of filtered documents is obtained.

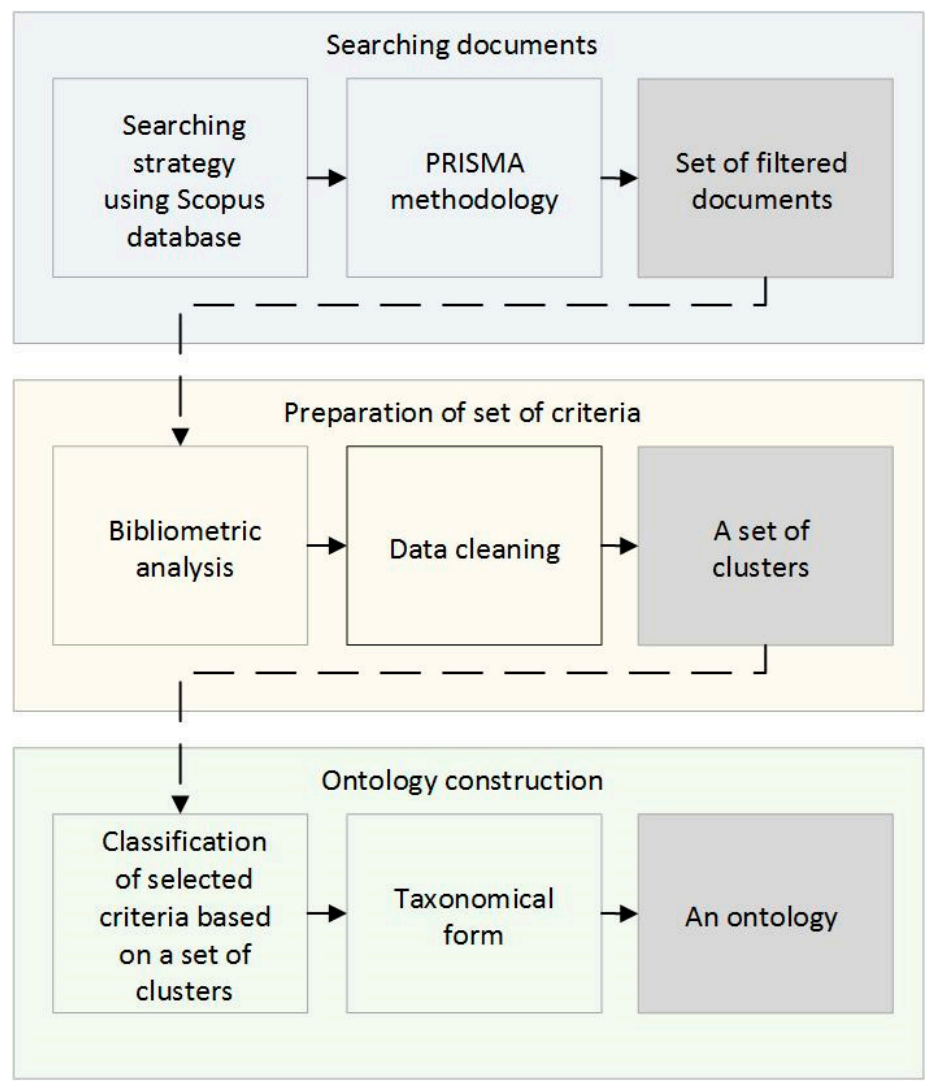

Figure 2. Research procedure.

The second part encompasses the bibliometric analysis of selected papers to retrieve and condense large amounts of bibliographic information. The output data is analyzed and is cleaned to create relevant and comprehensive information in the context of supplier selection and evaluation criteria. This means that the obtained results are revised, and consequently, further elaboration of harvested data is supported by affixture of rules and limitations. Finally, this process allowed to achieve a set of clusters with assigned criteria. In the third part, this set is a basis for further elaboration of a 
taxonomical form of knowledge, and, in the aftermath of this, an ontology. Each of the considered parts is fully described in the next sections.

\subsection{Search Strategy}

To obtain a high accuracy and quality of collected papers, the formal and structured methodology is used to provide the referenced top listed journals as a basis for data aggregation. PRISMA [92] methodology was used during the source documents selection process. PRISMA guarantees the objectivity of the conducted research and ensures avoidance of the lack of bias at the same time. PRISMA's main aim is to provide a specific guideline of conducting a systematic review. This process is determined by using a clearly formulated question that uses systematic and explicit methods to identify, select, and critically appraise relevant research [13]. Then, data obtained from the studies are collected and analyzed. To meet the research aims of this paper, an adaptation of PRISMA methodology is provided to conduct the systemic literature review for obtaining the most relevant documents containing the sets of criteria for green supplier selection and evaluation. Adapting PRISMA methodology ensures trustworthiness and repetitiveness of the systematic literature review [13].

When looking for particular criteria for the selection of green-oriented suppliers, the number of returned documents is huge in this area. In this searching process, the Scopus database was used to retrieve documents related to supplier selection and evaluation criteria. Overally, a number of 4026 documents were returned. Due to the fact that it is a young field of research, there were no restrictions in the settings. Hence, the year of publication of the selected documents is between 2007 and 2019. The conference reviews, erratum and review were excluded from the final set of documents. To feature a clear disparity between supplier selection and green supplier selection, in the initial search, the parameters were set up only to supplier selection or supplier evaluation. For this case, the query was as follows: (TITLE-ABS-KEY ("supplier selection") OR (TITLE-ABS-KEY ("supplier evaluation")). In view of the outcome, a number of 4026 documents were obtained. Due to the fact, that Scopus database does not provide duplicates, carrying out the process of identification allowed to acquire 4026 documents at the end. In this case, there are no additional records identified through other sources.

Refining the search process by adding additional criteria of greening provided a more detailed set of results. By the use of Boolean operator "AND", the following query was reached to evaluate the total number of publications related to green-oriented supplier selection and evaluation criteria; thus the query was as follows: (TITLE-ABS-KEY("green supplier selection") OR (TITLE-ABS-KEY ("green supplier evaluation") OR (TITLE-ABS-KEY ("green supplier criteria")). In this process, the specification of document characteristics and report characteristics were considered. Based on that, after the screening process, the set of 214 documents was retrieved for further consideration. Title and abstracts were screened and 20 studies were subsequently removed. Then, 194 full texts were assessed for eligibility. Only documents written in English and published as an article, conference paper or book chapter between 2007 and 2019 were considered. The main reason that the time period was set from 2007 was determined by the fact that using such defined query brought the first results from 2007. Four papers did not meet the requirements. Finally, the set contains 190 results of documents in the qualitative synthesis and the same number of documents was in the case of quantitative synthesis (meta-analysis). The extracted documents were exported to Excel spreadsheets. The results can be revised by the author name, affiliation, document type, source title, or subject area. The detailed steps are comprised in the previous section. A flow chart of study retrieval and selection is provided in Figure 3. 


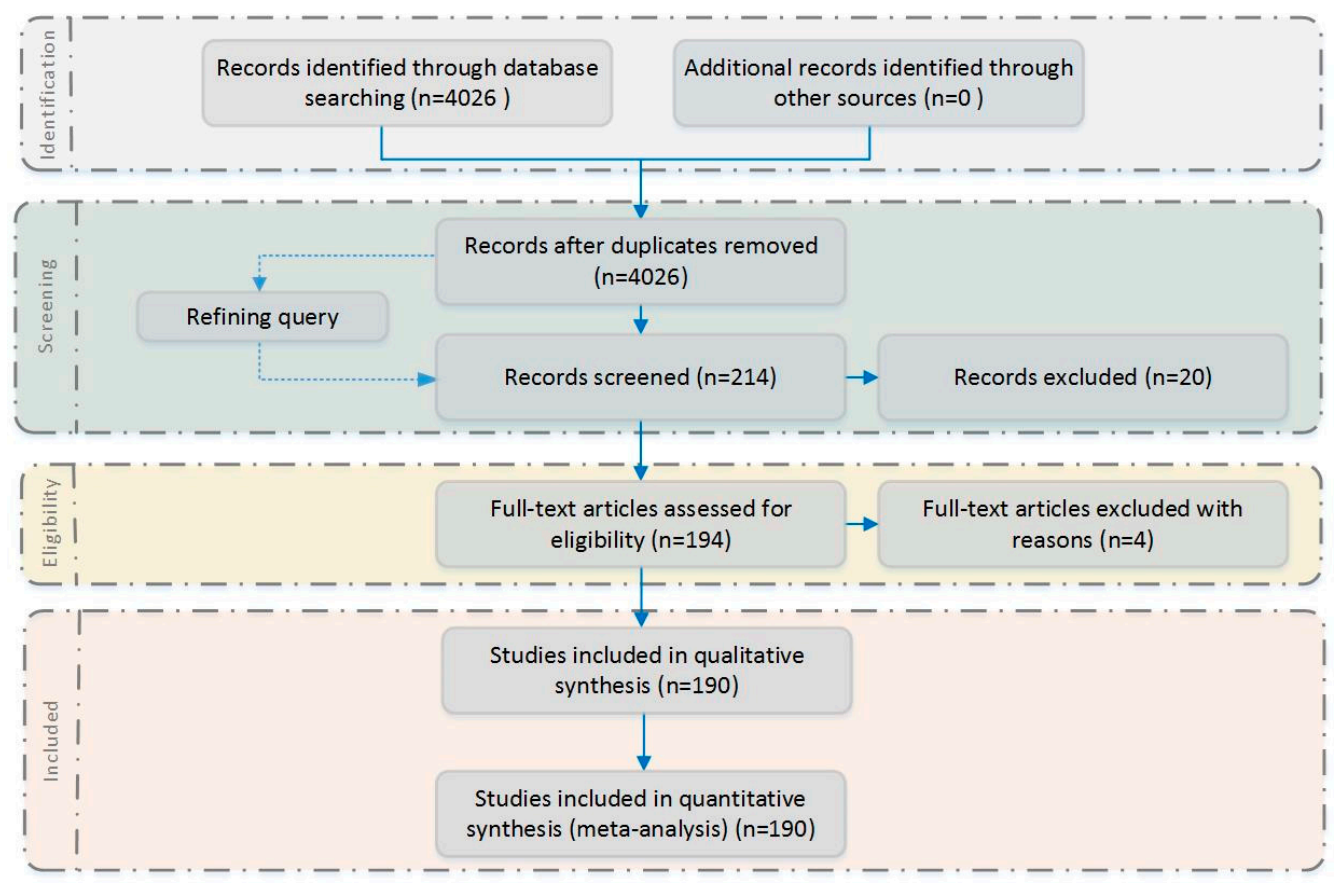

Figure 3. PRISMA steps.

\subsection{Preparation of a Set of Criteria Using Bibliometric Analysis}

The output data $[1,3-5,60,79,111-143]$ was analysed to create a map based on bibliographic data. The previously collected data was elaborated using the VOSviewer software [144]. The use of VOSviewer software allowed presenting the results in a form of comprehensive perspective about selected bibliometric documents. The bibliometric documents were presented in the overlay visualization according to the scores they reached. The lowest score ranged from blue to green to yellow representing the highest score. The colour bar indicates how scores are mapped to colours. The size of label is determined by the weight of an item. In Figure 4, the blue labels represent the papers from 2012 scanned according to the normalized citation ranking, whereas the light blue and green labels depict the papers published by authors after 2012. The light-green labels show the publications from 2016 to 2018, whereas yellow labels present the newest ones.

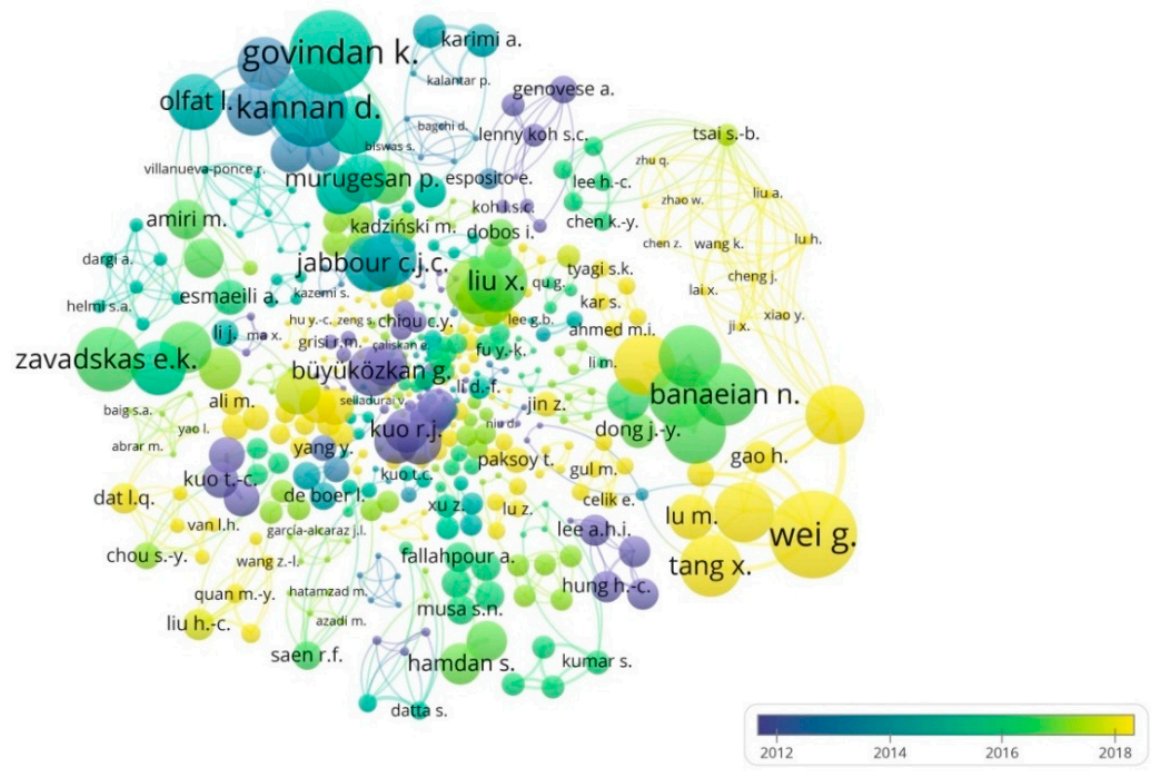

Figure 4. Analysis of the distribution of published articles. 
The resulting sample based on the analysis conducted over the Scopus database and related to green-oriented supplier selection and evaluation criteria comprises 190 documents. The majority of these documents were articles ( $74 \%$ of documents), followed by conference papers ( $20 \%$ of documents) and book chapters ( $3 \%$ of documents). The increase in this scientific field was observed after 2013, however this field is of growing interest.

The analysis of the distribution of research areas allows indicating the main fields of interests. The top five of published papers covers the field of Engineering ( $22 \%$ of documents), followed by Computer Science (17\% of documents), Business, Management and Accounting (14\% of documents), Mathematics (12\% of documents) and Decision Sciences (10\% of documents). The most prominent journal is Sustainability Switzerland, followed by Journal of Cleaner Production, Mathematical Problems in Engineering, Symmetry, Expert Systems with Applications, International Journal of Production Economics, and International Journal of Production Research. The remaining journals had less than 5 occurrences.

In terms of keyword occurrence, the results provided by Scopus database showed the frequency of used words. According to the analysis of the most occurred keywords, the Figure 5 displays the percentage results of the top ten most predominant keywords related to green-oriented supplier selection and evaluation. The decision making keyword ( 84 occurrences) and green supplier selection (80 occurrences) reached the highest rate of occurrence (covering $7 \%$ ), followed by green supplier selections (66 occurrences, covering 5\%), supply chain management (64 occurrences, covering $5 \%$ ), supplier selection ( 47 occurrences, covering $4 \%$ ) and supply chains (42 occurrences, covering $4 \%$ ). Due to similar meaning, the green supplier selection and green supplier selections can be joined together providing $12 \%$ of the total occurrences. The group 'others' contains the grouped other keywords referred to particular MCDA methods, generic algorithms and neural networks as well as statistical methods. The occurrences of each of the included elements are between 2 and 20.

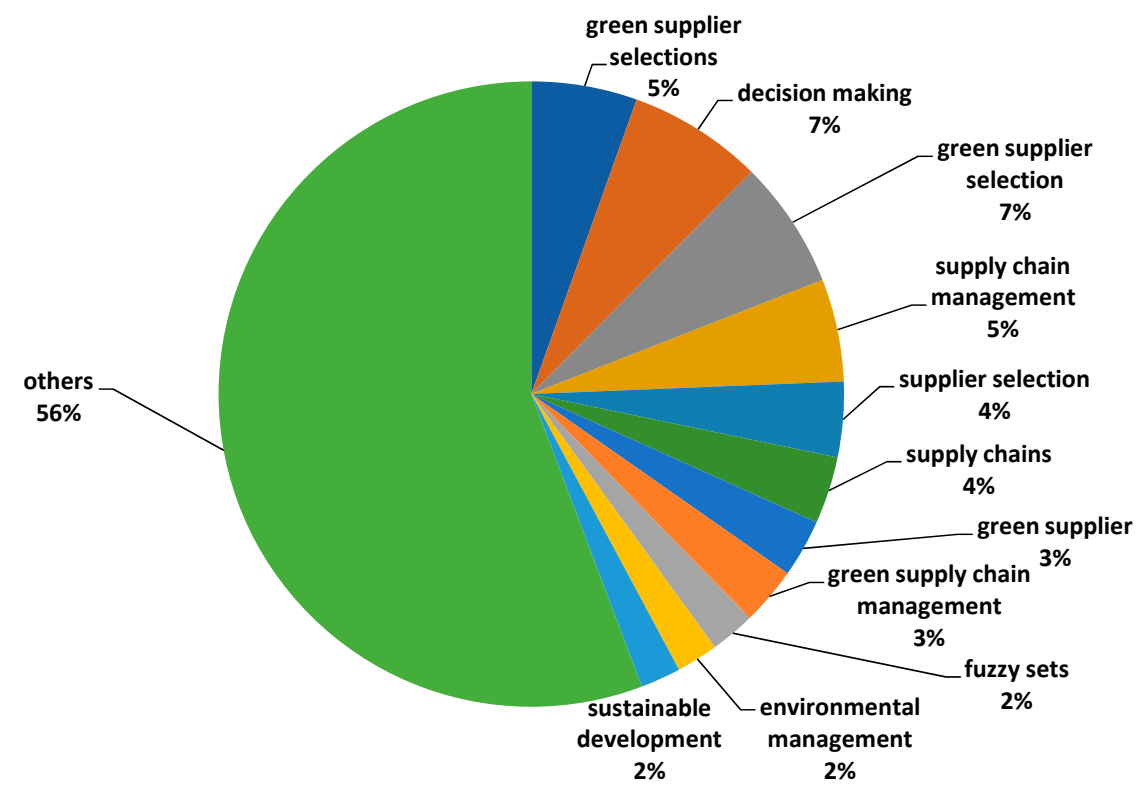

Figure 5. The results of the top ten most predominant keywords related to green-oriented supplier selection and evaluation.

To compare this, Figure 6 presents the keyword occurrences pointed out by authors of selected papers. This process was performed using VOSviewer software [144], and requires limiting the number of investigated keywords from 1093 to 267. The minimum number of occurrences of a keyword was 2 . In this case the threshold is fulfilled by 267 items. Accordingly, for each of the 267 keywords, the total strength of the co-occurrence links with other keywords is calculated. 


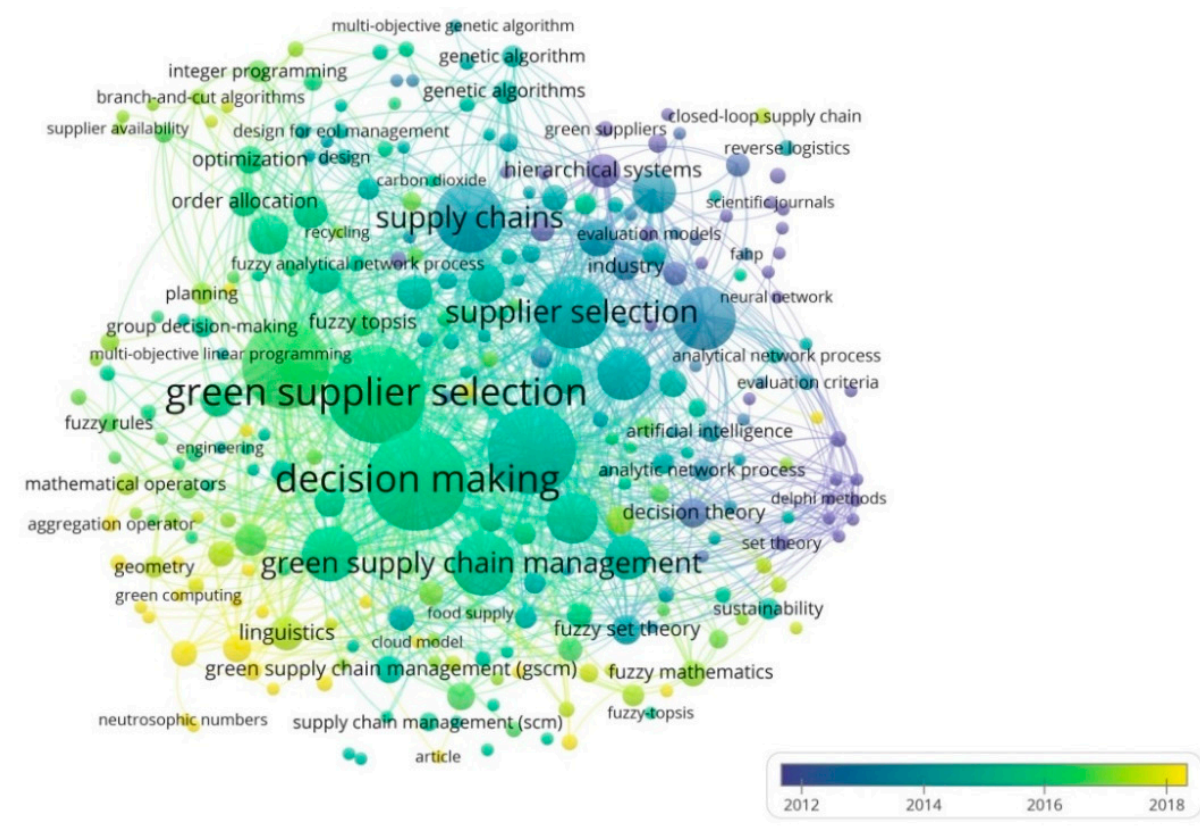

Figure 6. The keyword occurrences derived from bibliometric analysis.

\subsection{Filtering Results and Data Cleaning}

Due to the aim of the conducted research, a high impact was assigned to the supplier selection and evaluation criteria. According to the previously defined query, the conducted bibliometric analysis provided 190 document results. The output documents were analysed to create relevant and comprehensive information in the field of green-oriented supplier selection, and concomitantly they helped in the further process of manual selection of the most relevant sources. A number of investigated documents need to be filtered manually, because due to a complexity of selection process and accuracy of obtained results only this process guarantees appropriate selection of sources. The final set of contains 30 document papers filtered by provided useful content and 30 top cited journals. Each of the investigated papers provides information dedicated to green supplier selection and evaluation. Based on this, the collected data was elaborated in the form of distinguished main criteria and sub-criteria. Thus, the final set covers 520 criteria. The high level of their diversity indicates the complexity of the problem of choice of the green-oriented suppliers. These criteria are fundamentally different and show different aspects in the supplier selection process. The constructed set of criteria was a basis for further elaboration using VOSviewer software. Meanwhile, the criteria were collected in the form of main criteria and assigned sub-criteria. Further work required preparing and condensate the necessary information, and in the aftermath of this, a map based on network data. Thus, VOSviewer needs to be provided with data about the items in the network and the links between the items [144]. The items reflect the gathered criteria. The same match key was needed to link the prepared files together. This process will eventually lead to the construction of the map and to acquire a cluster classification of related items. This map was computed and normalized using an association strength method as an analysis method. This method is used for normalizing the strength of the links between items. It seems to be the most appropriate measure for normalizing co-occurrence frequencies $[144,145]$. This measure is called as the proximity index (e.g., [146,147]) or as the probabilistic affinity index (e.g., [145]). The level of location of the items was set by attraction and repulsion parameters, which influence on the way in which items are located in a map by the VOS layout technique [145].

Of the 520 items, 520 meet the threshold. The association strength method is used for normalizing the strength of the links between items. In this view, items are indicated by a label and, by default, also by a circle. The size of a label and its circle reflects its importance. Moreover, each item's circle is displayed in the colour of the item. The division of the items into groups corresponds with their 
specification. Finally, the set of 84 various clusters were defined. Each cluster contains the set of exactly the same items. The items represent the criteria that specify the supplier's selection and evaluation process. Items contain sub-items which are having the most intra-cluster co-occurrence relations related to them in any case. These sub-items are arranged in the same cluster. It gives an indicator of the way in which items within a cluster are related to each other. Furthermore, the volume of the circle in the map is an indicator of the contribution of the item. Colours indicate the cluster to which item was assigned by the clustering technique that was used. Apart from that, colours represent the groups of related items. The distance between items has a significant meaning, because the smaller distance between items, the higher number of colours. The distance between items enlightens the strong of their relatedness, whereas the size of a circle reflects an item's total number of co-occurrences.

The analysis of item distributions highlights the relatedness between items. Items that co-occur a lot, tend to be located close to each other in the visualization. Furthermore, the distribution is also influenced by the sub-item specifications.

Due to the fact that some clusters are located relatively close to each other, or overlapped them, Figure 7 presents the general view. Highlighting the parts of the view shows the proper colours of categorized items (e.g., cost is covered by financial item, and the threat seems to be blue, in the fact it is still green). Moreover, due to a huge number of identified clusters, the colours may be duplicated because of the limited colour palette. VOSviewer has grouped the terms into 84 clusters, of which 15 are of significant size. For example, the red cluster consists of criteria reflecting quality. It is the biggest cluster ( 57 items). The green cluster covers costs items (32 items), and then the orange cluster covers criteria related to benefits (21). Next, the blue cluster consists of terms related to finance (26), whereas the grey cluster refers to risk (24). A sub-item is belonging to each item. There are some cases when the sub-item is replicated, but the main difference is between the authorship of a given scientific paper. The final set of clusters is attached in supplementary materials (see: set_of_criteria.xls).

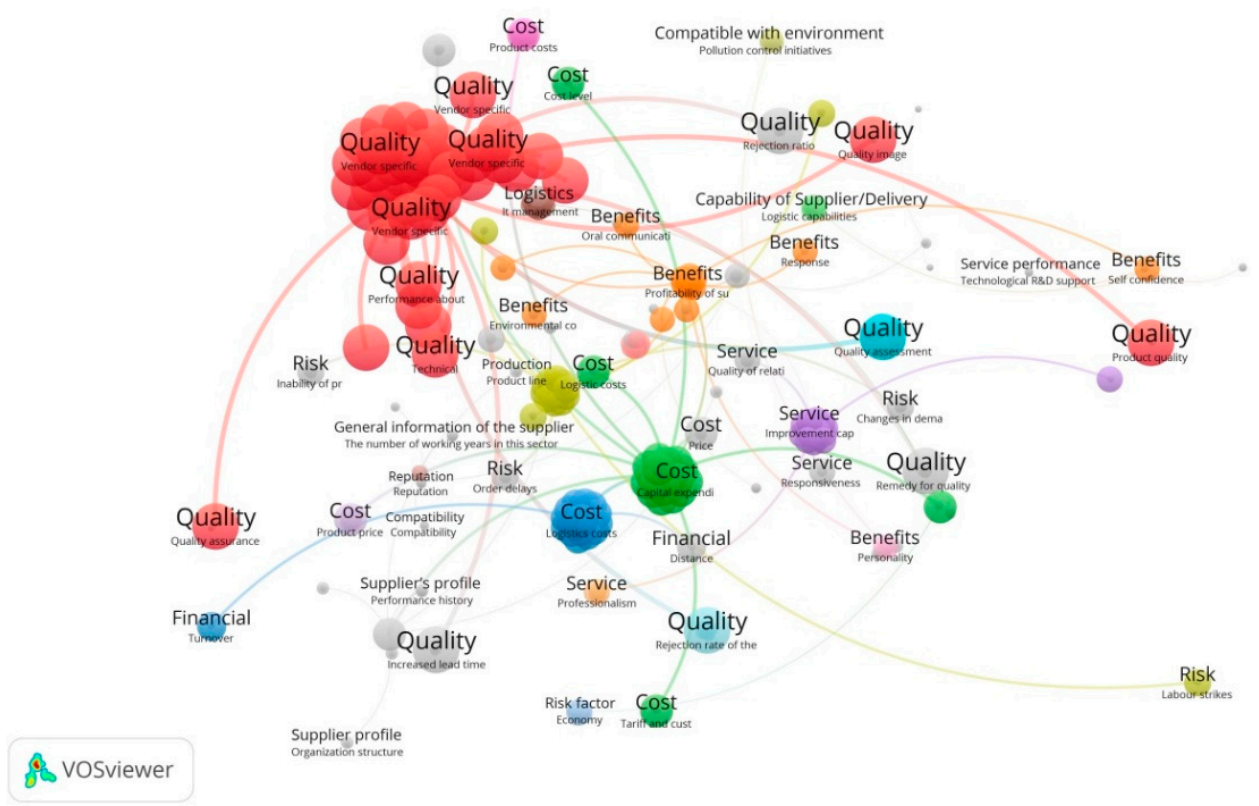

Figure 7. A set of clusters derived from bibliometric analysis.

Each of defined clusters is coded using a number from 1 to 84 (see: Supplementary Materials, set_of_criteria.xls). Based on the previously elaborated map using VOSviewer software [129], the process of categorization the information of the green-oriented supplier selection criteria performed the knowledge from the unstructured form into semi-structured. This was a basis to provide a full formal description of the domain knowledge. In order to achieve this, the set theory was used to ensure the detailed mathematical depiction [133]. For this purpose the mathematical background of 
the set theory is shown in Appendix A. The sets of 84 clusters are numbered from A6 to A88, whereas the general statements are shown from A1 to A5 Additionally technological form of elaborated model is presented in supplementary materials (see: ontology.owl).

\section{An Ontology for Green-Oriented Supplier Selection}

Although the ontology concept originated from philosophy, ontology was introduced into the fields of artificial intelligence, information system, knowledge management and others [148], becoming a necessary and important component of professional language in the computer field [149]. The aim of usage of ontology in the field of green-oriented supplier selection criteria is the assurance of knowledge capturing in this field, as well as providing a common understanding of this domain knowledge [27]. To meet this aim, ontology allows identifying common recognition vocabularies, and gives a clear definition of the relationship between these vocabularies from different levels of formal patterns [16]. Formally, ontology is defined as a set of instances and relations between them [150]. Giving the ontology formal description based on the set theory representation is widely adopted and presented in Section 4.2. An ontology's formal description requires specifying components such as individuals, classes, attributes and relations as well as restrictions, rules and axioms $[27,33]$. As a result, ontologies do not only introduce a sharable and reusable knowledge representation but can also add new knowledge about the domain, as well as they are capable of using a reasoning model [16,31]. Moreover, ontologies offer common understanding [150] of information gathered about green-oriented supplier selection criteria and that they make explicit domain assumptions.

A domain ontology defines a set of representational terms called concepts [150]. A well-defined construction of domain ontology requires to adapt a proper methodology. Various ontology construction approaches have been presented recently, offering a systemic and formal way to ontology construction, development and maintenance, i.e., Noy and McGuiness, METHONTOLOGY, and On-To-Knowledge $[28,151,152]$. Nevertheless common assumptions for a proper ontology design and construction are noticeable, for example term extraction, taxonomy construction and using competency questions to verify the coherence and correctness of constructed ontology $[26,27,149]$. The aim of the validation process is to provide activities of knowledge structuring and checks the correctness of the implemented knowledge base.

However, ontology construction remains a daunting task. In this paper, a general procedure of an ontology construction adapted from Noy and McGuiness was used [28]. It consists of the following phases: (1) defining a set of criteria, (2) taxonomy construction, (3) ontology construction, (4) formal description, (5) defined classes creation, (6) reasoning process, (7) consistency verification, (8) a set of results. Adapting these steps to green-oriented supplier selection domain, the first step requires us to specify domain and range, and to perform domain analysis. In this paper, this process was supported by PRISMA methodology [13] and bibliometric analysis by using a dedicated tool VOSviewer $[144,145]$ to remould the unstructured data, gathered from a wide range of scientific papers, into semi-structured form. Based on provided set of clusters and items assigned to them, the set of criteria and sub-criteria was conceptualized. Then, the specification of individuals (concepts), classes and relations as well as restrictions, rules and axioms from the scattered sources into a taxonomic form took place. Further implementation of ontology in a formal and structured way required to use one of the standard ontology languages, Ontology Web Language (OWL). Giving the ontology formal description, the Description Logic (DL) standard was used. The formal description of elaborated knowledge representation allows to machine-readable processing, sharing, reuse and finally populating new knowledge $[26,27,149,150,152]$. The formal representation captures domain knowledge about green-oriented supplier selection criteria and offers a wide spectrum to capitalize on the effects. To investigate the correctness of the proposed ontology, the competency questions are constructed and implemented using the Description Logic query mechanism. These activities allow verifying the coherence and correctness both of the constructed defined classes and the whole ontology using reasoning mechanisms. Consequently, at the end of this, the set of results was provided. 


\subsection{Taxonomy Construction}

A foundation for taxonomy construction was the concept clustering process of selected green criteria from documents collected from the Scopus database. Finally, the set of 84 clusters was constructed. To each item representing a single criterion in a cluster, a sub-item representing a sub-criterion was matched. Finally, they were organized in hierarchical form including main criteria and sub-criteria, distinctive for a given cluster. The basis for this classification was offered feature by a given cluster. The proposed taxonomy is dedicated to hierarchize knowledge about green-oriented criteria characterizing green suppliers as well as collecting this information in a holistic approach. Finally, apart from the 84 main criteria, 520 sub-criteria were defined and organized in a hierarchical way. The detailed description and list of criteria are described in Appendix A as well as in supplementary materials (see: set_of_criteria.xls). The aim of the proposed taxonomy is to ensure multi-dimensional aspects of green-oriented supplier selection criteria and also to offer multi-dimensional view of them. This taxonomy is a basis for the ontology construction, which is presented in detail below.

\subsection{Ontology}

The ontology construction process starts from extracting all the concepts from previously defined set of criteria and sub-criteria, and in the aftermath of this, defining properties and relations between them to form the backbone of the ontology. The main structure of the projected ontology is modelled on the Figure 8. The Protégé software [153] was applied to build the ontology. The applied technology standard is OWL. The source code (OWL/XML) is provided in [1].

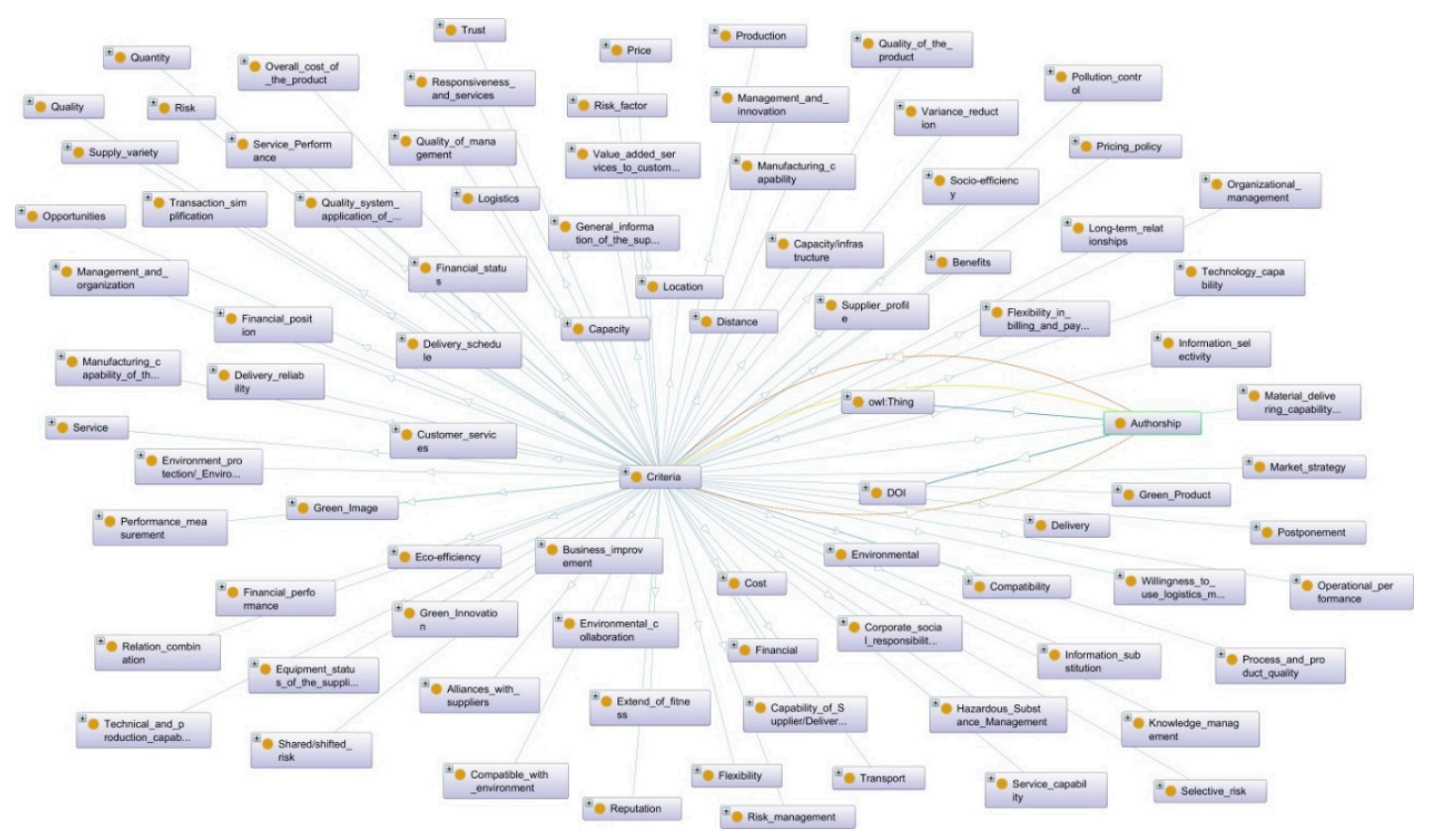

Figure 8. A set of named classes.

Each of the presented classes contains the set of sub-classes, as follows: 20 sub-classes-Benefits, 32-Cost, 1-Manufacturing capability, 6-Delivery reliability, 56-Quality, 3-Technology capability, 8-Customer services, 24-Risk, 4-Service performance, 7-Supplier's profile, 4-Risk factor, 26-Financial, 22-Service, 5-General information of the supplier, 4-Financial status, 2-Equipment status of the supplier, 4-Manufacturing capability of the supplier, 4-Material delivering capability of the supplier, 13-Quality system certificate of the supplier, 4-Selective risk, 4-Information selectivity, 4-Information substitution, 4-Transaction simplification, 4-Variance reduction, 4-Inventory velocity, 3-Postponement, 3-Shared/shifted risk, 11-Compatible with environment, 3-Trust, 13-Management and organization, 3-Capability of Supplier/Delivery, 4-Service 
capability, 5-Pricing policy, 4-Responsiveness and services, 3-Flexibility, 3-Technical and production capability, 2-Relation combination, 2-Organizational management, 5-Eco-efficiency, 6-Price, 10-Capacity/infrastructure, 2-Location, 9-Socio-efficency, 4-Knowledge management, 19-Delivery, 6-Quality of the product, 6-Delivery schedule, 3-Overall cost of the product, 2-Environmental collaboration, 12-Capability of Supplier/Delivery, 3-Production, 4-Market strategy, 4-Business improvement, 3-Extent of fitness, 1-Quantity, 15-Logistics, 12-Value-added services to customers, 4-Alliances with suppliers, 1-Environmental, 3-Process and product quality, 3-Management and innovation, 3-Financial position, 1-Capacity, 1-Transport, 1-Environment protection/environmental management, 4-Corporate social responsibility, 4-Pollution control, 8-Green product, 6-Green Image, 7-Green Innovation, 5-Hazardous substance management, 1-Compatibility, 1-Reputation, 1-Long-term relationships, 1-Operational performance, 1-Financial performance, 1-Risk management, 1-Performance measurement, 1-Willingness to use logistics manpower, 1-Flexibility in billing and payment, 1-Quality of management, 1-Supply variety, 1 -Distance.

The exemplary class Benefits has the following set: Profitability of supplier, Relationship closeness, Technological capability, Conformance quality, Conflict resolution, Emotional steadiness, Oral communication skill, Personality, Past experience, Product reliability, Environmental control, Response, Self-confidence, Flexibility, Product quality, On-time delivery, Production capability, Quality assurance system, Level of technology, Capability of supplying the urgent orders, Facility and technology. To ease distinguishing the concepts in the ontology, each of the sub-criteria is prefixed by the name of main criteria: Benefits as shown on Figure 9.

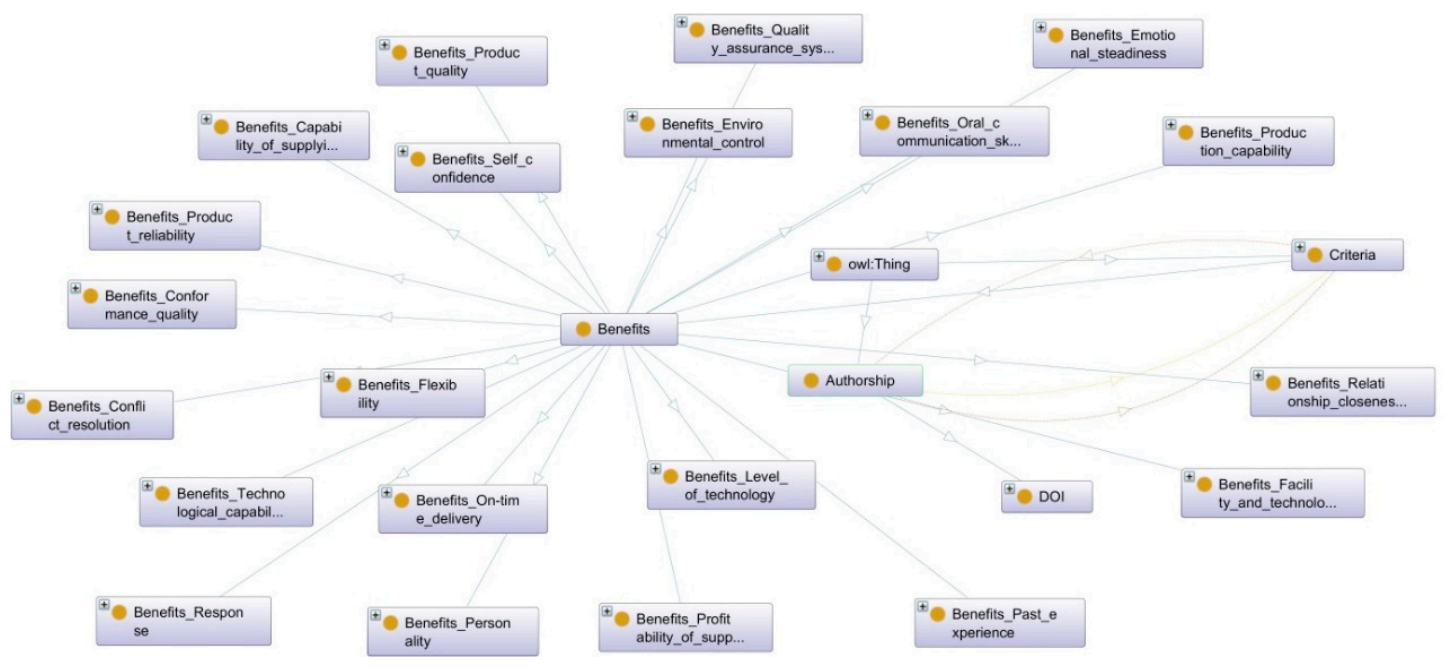

Figure 9. A sub-class representing aspects of benefits.

Another representative class Quality has the following sub-classes representing aspects of quality in green-oriented supplier selection criteria: Quality assurance, Rejection ratio, Rejection rate of the product, Increased lead time, Quality assessment, Remedy for quality problems, Quality image, Products quality, Product quality, Vendor specific, Operational, Technical, Quality of product, Quality of manufacturing, Product quality, Performance about quality rejections before delivery, Performance about quality rejections after delivery, Return rate, Discount rate, Quality, Low defect rate, Commitment to quality, Improved process capability, Quality Systems, Quality Assurance, Reject Rate, Warranties and Claim Policies, Capability of handling abnormal quality, and Commitment to quality. All sub-classes are depicted on Figure S1 as shown in Supplementary File S1.

The class Authorship contains the sub-class DOI (Figure S2, Supplementary File S1), which is a set of various digital object identifiers related to previously selected research papers. This form of identification is distinguished a high level of precision because of unambiguous meaning. 
However, inside the ontology there is more referenced information about considered papers (e.g., information about the authors, title of a paper, source title) as shown in Figure S3 in Supplementary File S1.

\subsection{Validation Process Using Competency Questions}

Description logic-based knowledge representation formalism is well suited for modelling domain knowledge in domain ontology in terms of concepts and properties. Moreover, the mechanisms based on description logic queries were adapted to present a validation process of the constructed ontology. A validation process verifies the ontologies formal structure and consistency with the domain knowledge in the context of green-oriented supplier selection criteria. To meet this aim, the competency questions are constructed and implemented using the Description Logic query mechanism. Rightness of achieved results approves the validation process and consequently provides the set of results.

The constructed ontology contains the specified list of green-oriented supplier selection criteria related to a given scientific publication and existing relations between them. Collecting the knowledge in one place supports the operational access to the distinguished features of green-oriented suppliers, implemented in the ontology. These determinants of the supplier selection process with green consideration are relatively different for various collaborating parties. Hence, this ontology is designed to determine prevalent general and environmental supplier selection criteria which can help decision makers to determine and prioritize suitable green supplier selection criteria, both general and detailed. Thus, the process of searching of preferred solutions starts with defining the green suppliers' favoured profile. In the green supplier selection process decision makers can use a collection of general and detailed criteria and add also new criteria and references to them. To do this in the constructed ontology, the specification set of criteria needs to be defined, and in the aftermath of this, implemented in the ontology.

For example, an organization is searching for new green-oriented supplier covering the area of flexibility ensuring technical capacity, area of quality offering return rate, features corresponding with responsiveness and services, especially ensuring responsiveness and attitude or optionally offering discount rate and benefits such as facility and technology. The result of usage of the constructed ontology is to provide a complete set of criteria supported with the bibliometric sources. The final set contains potential criteria and methodological background of selecting a supplier. Defining the necessary and sufficient conditions, and afterwards implementing it into the Protégé software permits on starting the reasoning process. The whole process requires using query algorithms to extract the valuable knowledge from ontology at the end of the reasoning process as shown on Supplementary File S2. Visualising the final ranking of the solutions presents on Figure 10, using OWLViz tool. Based on the experimentation results, the final set of the results is obtained. The orange color shows the defined class whereas the yellow displays the primitive classes. The class hierarchy is shown from left to right. The white arrows indicated the super classes as well. IS-A relations included in this figure linked between classes form a hierarchy of classes, a backbone of an ontology. In accordance with the constructed definition, only 3 references match these requirements. Any change in the preferred profile of green supplier requires modifying the definition (defined class). Implementing the definitions, reflecting the necessary and sufficient conditions enables providing the data-based results. More experimental queries are attached in Figures S6-S13 in Supplementary File S1.

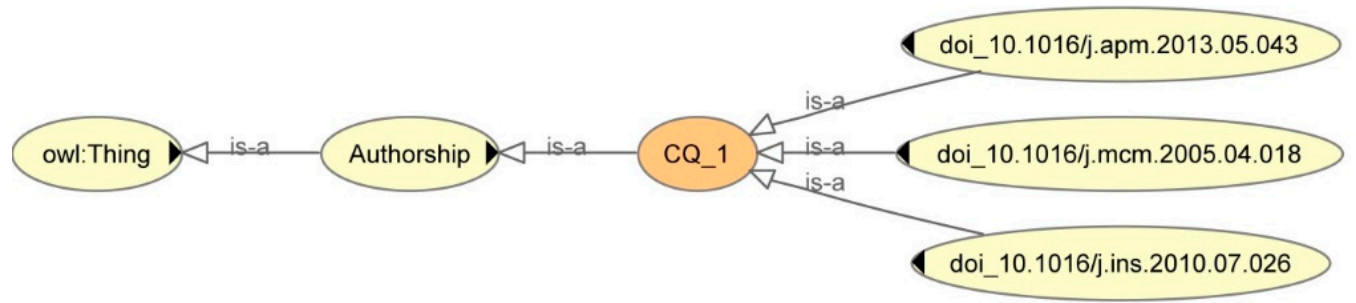

Figure 10. Visualising the final ranking of the solutions for the 1st competency question. 
A more complex example encompasses a green supplier profile containing 13 sub-criteria, as follows: quality, supplier profile offering customer base, offered responsiveness as a service, organizational and management issue such as inventory turnover ratio, rational price and quantity discount rate as cost factors, technical and production capability by the research and development (R\&D) rate as well as market strategy offering management ability, and optional fulfilment of customer services providing communication system, choice of transportation as a form of delivery, knowledge management by increasing order information sharing, green customers' market share and green product certifications. The results are obtained from a number of implemented instances of scientific papers and by queries on capabilities offered by the Description Logic Query, implemented in Protégé software as shown on Supplementary File S2. The query was built manually by the engineers based on their expertise. Visualising the final ranking of the solutions presents on Figure 11.

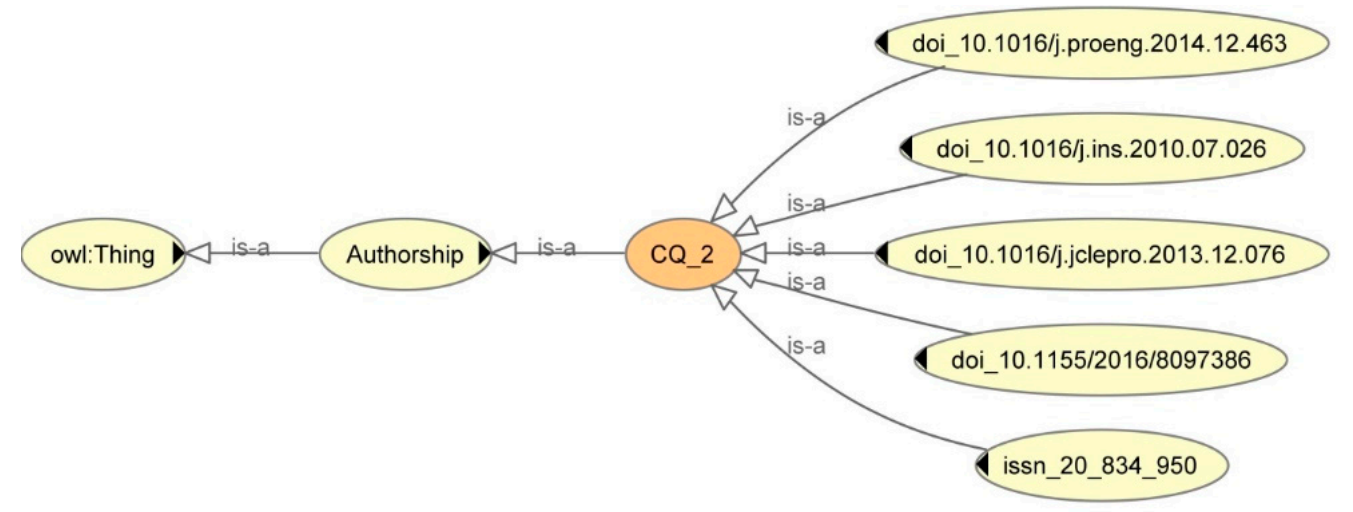

Figure 11. Visualising the final ranking of the solutions for the 2nd competency question.

Based on the experimentation results, the final set of the scientific papers is obtained. In accordance with the constructed definition, only five solutions match these requirements. The provided set contains the references to the criteria and methodological background of selecting a supplier. The selective competency questions approve the rightness of obtained results and the validation process and consequently provide the set of results. The proposed classification enclosed in the ontology, supports the rapid identification of the criteria to the green-oriented supplier selection. It is worth mentioning that there is considerable possibility to construct and implement various types of competency questions. The successful validation stage ensures both the consistency and correctness of the proposed ontology. The completeness of information offered by the constructed ontology based on the obtained results has been compared to the knowledge included in the set of criteria and sub-criteria characterizing green-oriented supplier selection.

The study demonstrated the usefulness of the proposed ontology of green-oriented supplier selection for real sets of criteria. The validation process has been satisfactory finished. The ontology-based model was built on basis of documents derived from Scopus database, and further elaborated using formal and systematic methodology. It should be noted that identifying the set of criteria directly depends on the current availability of data. In any case it is needed to constantly improve and enrich by new knowledge the proposed ontology-based model.

\subsection{Practical Implications of the Proposed Solution}

The elaboration of an ontology supporting green supplier selection provides the knowledge systematization of domain concepts-given/selected criteria and knowledge representation, and at times it highlights the advantages of interdisciplinary grounds to expert communication between systems. Furthermore, the formal structure of the ontology allows for systematic reasoning about concepts belonging to a given domain. This will mean that not only do we have the possibility to elaborate and build the model of a problem, but also we can replenish it by using the data from information systems. 
The elaborated ontology represents the up-to-date knowledge of the criteria of the green-oriented supplier selection domain, and consequently, it can provide a flexible platform to build or integrate information and other component-based information systems. For example:

- semantic connection with existing ontologies of particular supplier selection methods and automatic application of algorithms used;

- integration with repositories containing scientific papers of green supplier selection domain and information systems supporting decision-making processes and evaluation.

Integration of these components can lead to autonomic construction of information systems for assessment of the complete domain.

The practical implications of the proposed ontology encompass the attempts to incorporate a great amount of information about these criteria which determining green-oriented supplier selection and, therefore, is far more comprehensive in its detail than the source resources. This independent knowledge about criteria provided by the ontology can be incorporated into any database, knowledge base or information system holding knowledge. This means that the users can incorporate the data oriented on green supplier selection into their databases, integrate the data with the knowledge encapsulated in the ontology, and use it to interoperate with other databases. Moreover, the resulting knowledge representation in the form of an ontology makes the diffused resources about supplier selection criteria uniform and also classifies them into a coherent hierarchy.

\section{Conclusions}

With growing worldwide awareness of environmental protection, green-oriented collaboration in every part of the supply chain has become a leading component. Due to the fact that environmental protection and sustainable development are getting increasing attention in various sectors of industry, a good green supplier selection approach can help lessen the environmental risks and increase the competitiveness of a company. Many individual and integrated approaches have been proposed for supplier selection. Similarly, many sets of criteria were elaborated to improve this process. Although there is an abundance of studies considering the supplier selection, there are a rather limited number taking into account the environmental issues. Apart from this, a crucial element is knowledge accessibility and the accuracy of information available in transparent form. Capturing knowledge in one place in the form of ontology allows us to synthetize the criteria determining green-oriented supplier in one place, ensuring the ease of expanding this form of knowledge, as well as sharing it and its reusability. With regard to these issues, a domain knowledge conceptualization and formal foundations of an ontology for green supplier selection were presented.

The analysis of the literature confirmed the lack of knowledge issue in the scattered criteria determining green-oriented supplier selection. In response to this, the presented paper contains a successful attempt to conduct a formal and trustworthy bibliometric analysis and to build an ontology for green-oriented supplier selection. The proposed ontology constitutes formal guidelines for the selection of particular criteria determining green-oriented supplier selection. This process was conducted including three parts: searching documents and preparing of the set of criteria followed by ontology construction. This process was supported by a methodological background for capturing a high accuracy and quality of collected papers related to the considered domain by using the formal and structured methodology of PRISMA. This process aimed to provide a scientific value of conducted research. The further steps encompassed bibliometric analysis followed by filtering results and data cleaning. The final set contains 84 clusters with 520 criteria assigned. It allowed us to classify the selected criteria as well as to provide their formal notation. The motivation to undertake such activities was the need to obtain reliable scientific data for the ontology construction, preceded by the development of taxonomy. To validate the correctness of the ontology, a set of competency questions was implemented. This step addresses a validation stage and consistency checking of the elaborated 
ontology. The positive score of this process informs the well-defined ontology, providing at the end the final set of results. The solution is available at [1].

Concluding, the main contributions of the work include:

- the systematic and formal procedure of analysis of the available documents related to green-oriented supplier selection, with methodological background;

- the encapsulation of unstructured, semi-structured and structured knowledge about criteria determining green-oriented supplier selection;

- filling a gap between classical assumption of decision making and knowledge-based problem structuring by using the ontology as a form of problem solving in the scattered criteria determining green-oriented supplier selection;

- obtaining high accuracy of and quality of collected papers for data aggregation about criteria determining green-oriented supplier selection;

- elaboration of complete domain knowledge of criteria determining green-oriented supplier selection, with ease of expanding, reusing, multi-usage, sharing and handling, and publicly available;

- verification and consistency checking of the obtained ontology using competency questions.

The ontology presented provides independent knowledge about criteria for green-oriented supplier selection which is proved by scientific analysis of the literature. Meanwhile this knowledge can be incorporated into any database, knowledge base or information system holding knowledge associated to the green or sustainability domain. By solving this selection problem of the green-oriented supplier using ontology some gainings should be mentioned. For example, the possibility of a machine-readable access and handling semantic data can improve the searching capacity and knowledge sharing of the proposed ontology. In practical terms, the proposed ontology is featured by multi-use, reuse, and also knowledge sharing and dissemination.

All the same, further improvement of tihe presented ontology by adding up-to-date knowledge is the author's intention. The potential future works include the extension of the current collection of criteria. Probably the proposed ontology does not contain all the criteria available, despite taking them from the literature review. Thus, it imposes some duties for a systematic update and enriches by new knowledge the proposed ontology-based model, also exploiting other sources. However, the life-cycle of the knowledge base, its timeliness and usefulness requires undertaking actions that also involve the research community and practitioners, which the author tried to ensure by providing public access to the solution. The proposed ontology and its further usage, development and up-to-date depends on the involvement of the mentioned community input. Therefore, the author welcomes future readers to contribute to the ontology, by using the provided link by adding additional portions of new knowledge, because during the development of ontology, there is always the opportunity to enhance the veracity of data collection and enriching information.

From a technical point of view, a semantic integration with external reference knowledge sources using semantic annotations mechanisms could be a challenging, but promising task providing additional opportunities for expansion and development of the proposed solution. Hence, a promising approach is an expansion of this ontology of other domains, closely related with green aspects and sustainability. For example interesting way is to merge the proposed ontology with SA ontology published in [27]. Moreover, suggested future works should cover the extension of the proposed ontology towards knowledge handling in the field of methods supporting suppliers' selection and evaluation, whereas methodological appropriateness should be carefully analyzed using up-to-date ontology creation and evaluation methods and tools. This could lead to the development of a complete knowledge-based system supporting the handling of knowledge in the green and sustainability domain.

Supplementary Materials: The following are available online at http://www.mdpi.com/2071-1050/11/15/4208/s1, File S1: OWL code of the ontology: ontology.owl; The set of criteria determining supplier selection: the set of criteria: set_of_criteria.xls; File S2: The Set of Practical Use Cases. 
Funding: This research received no external funding.

Conflicts of Interest: The author declare no conflict of interest.

\section{Appendix A Classification of Selected Criteria}

This part presents the classification of selected criteria based on the set of clusters derived from bibliometric analysis and main assumptions of knowledge systematization for green-oriented supplier selection criteria. In the first part, a set of achieved clusters is shown, whereas the second part of Appendix A provides a formal description of the domain knowledge using the set theory.

Each of defined clusters is coded using a number from 1 to 84 (see: supplementary materials, set_of_criteria.xls). These items refer to the main criteria listed below. Based on the VOS viewer created map, the following clusters were identified: 1-Benefits, 2-Cost, 3-Manufacturing capability, 4-Delivery reliability, 5-Quality, 6-Technology capability, 7-Customer services, 9-Risk, 10-Service performance, 11-Supplier's profile, 12-Risk factor, 13-Financial, 14-Service, 15-General information of the supplier, 16-Financial status, 17-Equipment status of the supplier, 18-Manufacturing capability of the supplier, 19-Material delivering capability of the supplier, 20-Quality system certificate of the supplier, 21-Selective risk, 22-Information selectivity, 23-Information substitution, 24-Transaction simplification, 25-Variance reduction, 26-Inventory velocity, 27-Postponement, 28-Shared/shifted risk, 29-Compatible with environment, 30-Trust, 31-Management and organization, 32-Capability of Supplier/Delivery, 33-Service capability, 34-Pricing policy, 35-Responsiveness and services, 36-Flexibility, 37-Technical and production capability, 38-Relation combination, 39-Organizational management, 40-Eco-efficiency, 41-Price, 42-Capacity/infrastructure, 43-Location, 44-Socio-efficency, 45-Knowledge management, 46-Delivery, 47-Quality of the product, 48-Delivery schedule, 49-Overall cost of the product, 50-Environmental collaboration, 51-Capability of Supplier/Delivery, 52-Production, 53-Market strategy, 54-Business improvement, 55-Extent of fitness, 56-Quantity, 57-Logistics, 58-Value-added services to customers, 59-Alliances with suppliers, 60-Environmental, 61-Process and product quality, 62-Management and innovation, 63-Financial position, 64-Capacity, 65-Transport, 66-Environment protection/environmental management, 67-Corporate social responsibility, 68-Pollution control, 69-Green product, 70-Green Image, 71-Green Innovation, 72-Hazardous substance management, 73-Compatibility, 74-Reputation, 75-Long-term relationships, 76-Operational performance, 77-Financial performance, 78-Risk management, 79-Performance measurement, 80-Willingness to use logistics manpower, 81-Flexibility in billing and payment, 82-Quality of management, 83-Supply variety, 84-Distance. The final set of clusters is attached in supplementary materials (see: set_of_criteria.xls).

In the domain and range of a relation, if $R$ is a relation from set $T p(A u)$ and $A(C)$, then the set of all taxons (all of the first components of the ordered pairs) belonging to $\mathrm{R}$ is called the domain of $\mathrm{R}$. Thus, Dom is defined as follows:

$$
(\mathrm{R})=\{\mathrm{au} \in \mathrm{Au}:(\mathrm{au}, \mathrm{c}) \in \mathrm{R} \text { for some } \mathrm{c} \in \mathrm{C}\},
$$

The set of all second components of the ordered pairs (the set of all taxons) belonging to $\mathrm{R}$ is called the range of $\mathrm{R}$. Thus, the range of $\mathrm{R}$ is defined as follows:

$$
R=\{c \in C:(t x, c) \in R \text { for some } t x \in T\},
$$

If authorship $\mathrm{Au}$ and criteria $\mathrm{C}$ are two non-empty sets, then the Cartesian product $\mathrm{T}$ of $\mathrm{Au}$ and $\mathrm{C}$, denoted $\mathrm{Au} \times \mathrm{C}$, is the set of all ordered pairs (au, c) such that au $\in \mathrm{Au}$ and $\mathrm{c} \in \mathrm{C}$ :

$$
A u \times C=\{(a u, c): a u \in A U, c \in C\},
$$

Type Au contains the finite set of taxons, which are subsets: 
$\mathrm{Au}=\{$ Doi1, Doi2, Doi3, Doi4, Doi5, Doi6, Doi7, Doi8, Doi9, Doi10, Doi11, Doi12, Doi13, Doi14, Doi15, Doi16, Doi17, Doi18, Doi19, Doi20, Doi21, Doi22, Doi23, Doi24, Doi25, Doi26, Doi27, Doi28, Doi29, Doi30, Doi31, Doi32, Doi33, Doi34, Doi35, Doi36, Doi37, Doi38\},

where the subsets are as follows: Doi1-10.1016/j.ijpe.2005.03.009, Doi2-10.1016/S0165-0114[97]00377-1, Doi3-978 837875156 4, Doi4-10.1016/j.fss.2006.11.015, Doi5-10.1016/j.fss.2007.09.008， Doi6-10.1016/j.ijar.2006.04.001， Doi7-10.1155/2016/8097386， Doi8-10.1108/JMTM-02-2012-0015， Doi9-10.1016/j.omega.2005.08.004, Doi10-10.1016/S0969-7012[97]00034-8, Doi11-10.1016/j.mcm.2005.04.018, Doi12-10.1016/j.apm.2006.10.002， Doi13-10.1016/S0305-0483[00]00039-6， Doi14-23 194 847, Doi15-10.1016/S1366-5545[98]00012-X， Doi16-10.22436/jmcs.002.01.12， Doi17-23 067 276, Doi18-10.3926/jiem.2008.v1in2.p54-76, Doi19-10.1109/HICSS.2011.35, Doi20—20 834 950， Doi21-10.1016/j.apm.2013.05.043， Doi22-10.1016/j.ins.2010.07.026， Doi23-10.1016/j.ijepes.2012.08.045, Doi24-10.1016/j.cie.2014.10.005, Doi25-10.1016/j.cie.2014.10.013, Doi26-10.1016/j.ejor.2012.09.037, Doi28-10.1016/j.eswa.2010.06.021, Doi27-10.1016/j.resconrec.2012.02.009, Doi30-10.1016/j.eswa.2011.03.027, Doi32-10.1016/j.jclepro.2014.05.040, Doi34-10.1016/j.procs.2014.05.317, Doi36-10.1016/j.jclepro.2013.12.076, Doi38-10.1016/j.ejor.2007.01.018.

In the cases of partial lack of knowledge about the full bibliographical description, in the set of references provided the author decided to replace the DOI number into existing ISBN/ISSN identifier. The full description of each of related sources is included in the ontology annotations.

Criteria C contain the finite set of taxons, defined as follows:

$C=\{B, C, M c, D r, Q, T c, C s, R, S p, S p p, R f, F, S$, Gis, Fs, Ess, Mcs, Mdc, Qsc, Sr, Is, Isb, Ts, Vr, Iv, P, Ssr, Ce, T, Mo, Csd, Sc, Pp, Rs, Fx, Tpc, Rc, Om, Ee, Pr, Ci, L, Se, Km, D, Qp, Ds, Ocp, Ec, Cd, Po, Ms, Bi, Ef, Qt, L, Va, As, Ev, Ppq, Mi, Fp, Cp, Tr, Epm, Csr, Pc, Gp, Gi, Gin, Hsm, Cmp, Rp, Ltr, Op, Fpr, Rm, Pm, Wlm, Fbp, Qm, Sv, D\},

where the following subsets are included: B-Benefits, C-Cost, Mc-Manufacturing capability, Dr-Delivery reliability, Q-Quality, Tc-Technology capability, Cs-Customer services, R-Risk, Sp-Service performance, Spp-Supplier's profile, Rf-Risk factor, F-Financial, S-Service, Gis-General information of the supplier, Fs-Financial status, Ess-Equipment status of the supplier, Mcs-Manufacturing capability of the supplier, Mdc-Material delivering capability of the supplier, Qsc-Quality system certificate of the supplier, Sr-Selective risk, Is-Information selectivity, Isb-Information substitution, Ts-Transaction simplification, Vr-Variance reduction, Iv-Inventory velocity, P-Postponement, Ssr-Shared/shifted risk, $\mathrm{Ce}-$ Compatible with environment, T-Trust, Mo-Management and organization, Csd-Capability of Supplier/Delivery, Sc-Service capability, Pp-Pricing policy, Rs-Responsiveness and services, Fx-Flexibility, Tpc-Technical and production capability, Rc-Relation combination, Om-Organizational management, Ee-Eco-efficiency, Pr-Price, Ci-Capacity/infrastructure, L-Location, Se-Socio-efficency, Km-Knowledge management, D-Delivery, Qp-Quality of the product, Ds-Delivery schedule, Ocp-Overall cost of the product, Ec-Environmental collaboration, Cd-Capability of Supplier/Delivery, Po-Production, Ms-Market strategy, Bi-Business improvement, Ef-Extent of fitness, Qt-Quantity, L-Logistics, Va-Value-added services to customers, As-Alliances with suppliers, Ev-Environmental, Ppq-Process and 
product quality, Mi-Management and innovation, $\mathrm{Fp}-$ Financial position, $\mathrm{Cp}-$ Capacity, $\mathrm{Tr}$-Transport, Epm-Environment protection/environmental management, Csr-Corporate social responsibility, Pc-Pollution control, Gp-Green product, Gi-Green Image, Gin-Green Innovation, Hsm-Hazardous substance management, Cmp-Compatibility, Rp—Reputation, Ltr-Long-term relationships, Op-Operational performance, Fpr-Financial performance, Rm-Risk management, Pm-Performance measurement, Wlm-Willingness to use logistics manpower, Fbp-Flexibility in billing and payment, Qm-Quality of management, $\mathrm{Sv}$-Supply variety, D—Distance.

The final set of clusters with assigned sub-criteria is attached in supplementary materials (see: set_of_criteria.xls). Based on the investigated clusters, the classification of sub-criteria is as follows:

- $\quad B$ is defined as a separated set of Benefits, with formal presentation presented below:

$$
\begin{gathered}
B=\{B p, B r c, B t c, B c q, B c r, B e s, B o c, B p s, B p e, B p r, B e c, B r, B s c, B f, B p q, B o t d, B p c, \\
\text { Bqas, Blt, Bco, Bft }\},
\end{gathered}
$$

where the subsequent abbreviations were used as follows: Bp Profitability of supplier, Brc-Relationship closeness, Btc-Technological capability, Bcq-Conformance quality, Bcr-Conflict resolution, Bes-Emotional steadiness, Boc-Oral communication skill, Bps-Personality, Bpe-Past experience, Bpr-Product reliability, Bec-Environmental control, $\mathrm{Br}$-Response, Bsc-Self-confidence, Bf-Flexibility, Bpq-Product quality, Botd-On-time delivery, Bpc-Production capability, Bqas-Quality assurance system, Blt-Level of technology, Bco-Capability of supplying the urgent orders, Bft-Facility and technology).

- C represents a separated set of Cost formally presented as:

$$
\begin{gathered}
\mathrm{C}=\{\mathrm{Cc}, \mathrm{Cpc}, \mathrm{Coc}, \mathrm{Clc}, \mathrm{Clc}, \mathrm{Cprc}, \mathrm{Casc}, \mathrm{Cpp}, \mathrm{Ctcd}, \mathrm{Cp}, \mathrm{Ccl}, \mathrm{Cph}, \mathrm{Cspp}, \mathrm{Ccd}, \\
\text { Cce, Coe, Csc, Cdc, Cic, Cgpr, Cqdr, Capp, Ccrc }\},
\end{gathered}
$$

where the symbols mean as follows: Cc-Cost, Cpc-Product cost, Coc-Ordering cost, Clc-Logistics costs, Cprc-Price/Cost, Casc-After sales costs, Cpp-Product price, Ctcd-Tariff and custom duties, $\mathrm{Cp}$-Price, Ccl-Cost level, Cphc-Purchase costs, Cspp-Suppliers production pauses, $\mathrm{Ccd}-\mathrm{Customers} \mathrm{dissatisfaction,} \mathrm{Cce}-\mathrm{Capital}$ expenditure, $\mathrm{Coe}-$ Operating expenditure, Csc-Sunk cost, Cdc-Direct cost, Cic-Indirect cost, Cgpr-Gross profit rate, Cqdr-Quantity discount rate, Capp-Appropriateness of the product price to the market price, Ccrc-Cost reduction capability.

- Mc refers to one-element set of Manufacturing capability:

$$
\mathrm{Mc}=\{\mathrm{Mcm}\},
$$

where Mcm refers to Manufacturing capability.

- Dr represents a set of Delivery reliability with formal presentation as follows:

$$
\operatorname{Dr}=\{\text { Drl, Drt }\},
$$

where Drl refers to Lead time, and Drt means On time delivery.

- $\mathrm{Q}$ is defined as a separated set of Quality, with proper presentation as follows:

$$
\begin{gathered}
\mathrm{Q}=\{\mathrm{Qa}, \mathrm{Qrr}, \text { Qrrp, Qild, Qas, Qrqp, Qqi, Qpq, Qvs, Qo, Qt, Qqp, Qqm, Qpq, Qprb, } \\
\text { Qpra, Qrt, Qdt, Qq, Qldt, Qcq, Qipc, Qqs, Qrjr, Qwcp, Qchq, Qcq }\}
\end{gathered}
$$

where the subsequent abbreviations were used: Qa-Quality assurance, Qrr-Rejection ratio, Qrrp-Rejection rate of the product, Qild-Increased lead time, Qas-Quality assessment, Qrqp—Remedy for quality problems, Qqi-Quality image, Qpq-Product quality, Qvs—Vendor 
specific, Qo-Operational, Qt-Technical, Qqp-Quality of product, Qqm-Quality of manufacturing, Qpq-Product quality, Qprb-Performance about quality rejections before delivery, Qpra-Performance about quality rejections after delivery, Qrt-Return rate, Qdt-Discount rate, Qq-Quality, Qldt—Low defect rate, Qcq-Commitment to quality, Qipc-Improved process capability, Qrjr-Quality Systems, Reject Rate, Qwcp-Warranties and Claim Policies, Qchq-Capability of handling abnormal quality, Qcq-Commitment to quality).

- Tc represents a set of Technology capability defined as follows:

$$
\mathrm{Tc}=\{\mathrm{Tcl}, \mathrm{Tcrd}, \mathrm{Tcc}\},
$$

where Tcl refers to Technology level, Tcrd shows Capability of R\&D, and Tcc represents Capability of design.

- Cs is a separated set of Customer services, formally defined as follows:

$$
\mathrm{Cs}=\{\mathrm{Csrs}, \mathrm{Csws}, \mathrm{Cscs}\},
$$

where Csrs refers to Response to complaints, Csws represents Warranty support, and Cscs denotes Communication system.

- $\quad \mathrm{O}$ is defined as a separated set of Opportunities, with formal presentation as follows:

$$
\mathrm{O}=\{\text { Osc, Osd, Oimc, Ofg, Oiec, Ossi, Ojg, Oti }\}
$$

where the abbreviations represent the resulting elements: Osc-Supplier collaboration, Osd-Supplier development, Oimc-Increase in manufacturing capacity, Ofg-Financial growth, Oiec-Improvement and ease of communication, Ossi-Service support improvement, Ojg-Joint growth, Oti-Technological improvement.

- $\quad \mathrm{R}$ is defined as a separated set of Risk, with appropriate presentation as follows:

$$
\begin{gathered}
R=\{\text { Rcd, Rcc, Rfr, Rfs, Rmb, Rls, Rod, Ripf, Rgl, Rps, Recc, Rcr, Rfri, Rnd, Rtr, Rdr, } \\
\text { Rsc, Rbsc, Ri, Rvp, Rspi, Rcc, Ruo, Rsp },
\end{gathered}
$$

where the subsequent abbreviations were used as follows: Rcd-Changes in demand, Rcc-Customer complaints, Rfr-Field return, Rfs-Financial strength, Rmb-Machine break down, Rls-Labour strikes, Rod-Order delays, Ripf-Inability of production flexibility, Rgl-Geographical location, Rps-Political stability, Recc-Equipment capacity change, Rcr-Country risk, Rfri-Financial risk, Rnd-Natural disasters, Rtr-Technology risk, Rdr-Delivery risk, Rsc-Supply constraint, Rbsc-Buyer supplier constraint, Ri-Inconsistency, Rvp-Variation in price, Rspi-Suppliers production imitations, Rcc-Cutting cooperation, Ruo-Uncompleted order, Rsp-Suppliers profile.

- $\quad$ Sp represents a set of Service performance defined as follows:

$$
\mathrm{Sp}=\{\mathrm{Spd}, \mathrm{Spt}, \mathrm{Spr}, \mathrm{Spe}\}
$$

where Spd refers to Delivery schedule, Spt represents Technological R\&D support, Spr means Response to change, and Spe denotes Ease of communication.

- Spp is defined as a separated set of Supplier profile, with appropriate presentation as follows:

$$
\mathrm{Spp}=\{\mathrm{Sppf}, \mathrm{Sppc}, \mathrm{Sppp}, \mathrm{Sppf}, \mathrm{Sppo}, \mathrm{Sppn}, \mathrm{Spps}\},
$$

where the subsequent abbreviations were used as follows: Sppf-Financial status, Sppc-Customer base, Performance history, Production facility and capacity, Organization structure, The number of personnel, Education status of the personnel). 
- Rf reflects to a set of Risk factor, presented below:

$$
R f=\{R f g, R f p, R f e, R f t\},
$$

where Rfg means Geographical location, Rfp denotes Political stability, Rfe presents Economy, and Rft depicts Terrorism.

- $\quad F$ is defined as a separated set of Financial, with specified presentation as follows:

$$
\begin{gathered}
F=\{F t, F d, \text { Ffm, Ffp, Ffs, Ffp, Fcs, Frv, Fuo, Ffc, Fcw, Ffc, Fvc, Fcer, Ffce, Fsw, Frl, Ftc, } \\
\text { Frs, Ffst }\}
\end{gathered}
$$

where the following subsets are shown as consequent: Ft—-Turnover, Fd—Distance, Ffm—Financial of manufacturing, Ffp-Financial of product, Ffs-Financial strength, Ffp-Financial position, Fcs-Cost saving, Frv-Recapturing value, Fuo-Unit operation cost, Ffc-Fixed cost of maintaining a warehouse, Fce-Cost of establishing a warehouse, Fcw-Fixed cost of expanding a warehouse, Fvc - Variable cost of expanding a warehouse Fixed cost of maintaining a repair facility, Fcer-Cost of establishing a repair facility, Ffce-Fixed cost of expanding a repair, Fsw-Savings from the use of an existing warehouse as a repair facility, Frl-Reverse logistics cost, Ftc-Total cost of shipments, Frs-Revenue from the sale of recyclables, Ffst-Financial stability).

- $\quad \mathrm{S}$ is defined as a separated set of Service with itemized presentation as follows:

$$
\mathrm{S}=\{\mathrm{Sd}, \mathrm{Src}, \mathrm{Sp}, \mathrm{Sq}, \mathrm{Sr}, \mathrm{Si}, \mathrm{Sa}, \mathrm{Ss}, \mathrm{Ssd}, \mathrm{Sr}, \mathrm{Sic}, \mathrm{Sod}, \mathrm{Sqr}, \mathrm{Ssc}, \mathrm{Sro}, \mathrm{Srd}, \mathrm{Sdi}, \mathrm{Spu}, \mathrm{Sfl}, \mathrm{Spf}, \mathrm{Ssq}\},
$$

where the following subsets are shown as consequent: Sd—Delivery on time, Src-Responsiveness to customer needs, Sp-Professionalism of sales person, Sq-Quality of relationship with vendor, $\mathrm{Sr}-$ Response to demand, Si-Information acquisition, Sa-After-sales service, Ss-Service, Ssd-Service standard, Sr-Responsiveness, Sic—Improvement capability, Sod—On time delivery, Sqr-Quick responsiveness, Ssc-Supplier capacity, Sro-Rate of processing order form, Srd-Rate of delivery in time, Sdi-Degree of information modernized, Spu—Punctuality, Sfl—Flexibility, Spf-Price Fairness, Ssq—Service quality).

- Gis refers to a set representing General information of the supplier, with the specified elements:

$$
\text { Gis }=\{\text { Gisf, Gisw, Gisr, Giss, Gisc }\} \text {, }
$$

where Gisf presents Facility location, Gisw means The number of working years in this sector, Gisr shows References, Giss refers to The service capability, and Gisc denotes Communication capability.

- Fs represents a set of Financial status defined as follows:

$$
\text { Fs }=\{\text { Fsp, Fse, Fsa }\}
$$

where the following subsets are noted as particulars: Fsp-The last term profit, Fse-Exporting status, Fsa-Appropriateness of the materials price to the market price.

- Ess represents a set of Equipment status of the supplier, defined subsequently:

$$
\text { Ess }=\{\text { Essm, Esst }\}
$$

where Essm means Machine capacity and capability, and Esst presents Manufacturing technology;

- Mcs presents a set of Manufacturing capability of the supplier defined as follows:

$$
\text { Mcs }=\{\text { Mcsf, Mcst, Mcsp, Msch }\} \text {, }
$$


where Mcsf means Facilities manufacturing capacity, Mcst represents Technical capability, Mscp shows Manufacturing planning capability, and Msch refers to Handling and packaging capability.

- Mdc refers to a subset of Material delivering capability of the supplier defined subsequently:

$$
\operatorname{Mdc}=\{\text { Mdcq, Mdcd, Mdcp, Mdcm }\},
$$

where Mdcq presents Appropriateness of the quantity, Mdcd means Appropriateness of the delivery date, Mdcp denotes Appropriateness of the packaging standards, and Mdcm shows The period of procuring materials.

- Qsc is defined as a set of Quality system certificate of the supplier with specified subsets:

$$
\text { Qsc }=\{\text { Qscs, Qscm, Qscd, Qsca, Qscu, Qscp, Qsci, Qscr, Qscc, Qscn, Qscp, Qscau, Qsct }\},
$$

where the following subsets are shown as consequent: Qscs-Quality system certificate of the supplier, Qscm-Quality manual, Qscd-Documentation control, Qsca-Archive of quality records, Qscu-Usage of worth instructions, Qscp-Process control capability, Qsci-Product identification, Qscr-Receiving Inspection, Qscc-Calibration control, Qscn-Non-conforming material control system, Qscp-Corrective and preventive action system, Qscau-Audit mechanism, Qsct-Training.

- Sr represents a set of Selective risk, specified as follows:

$$
\mathrm{Sr}=\{\text { Srk, Srkc, Srks, Srki }\},
$$

where the following subsets are shown using the symbols: Srk-Knowledge about customer, Srkc-Knowledge about competition, Srks-Service range capabilities, Srki-Inventory management system flexibility.

- Is contains a set of elements of Information selectivity, which is formally describes as:

$$
\text { Is }=\{\text { Isf, Isa, Isd, Iss }\},
$$

where Isf means Flexibility of data linkages, Isa represents Accuracy of data, Isd denotes Accuracy of data needs, and Iss refers to Data search capability.

- Isb refers to a set of Information substitution, formally defined as a set of elements:

$$
\mathrm{Isb}=\{\mathrm{Isbc}, \mathrm{Isca}, \mathrm{Isbl}, \mathrm{Isbf}\},
$$

where the elements are noted as follows: Isbc-Coverage of information linkages, Isca-Accuracy of data, Isbl—Level of system integration, Isbf—Forecasting capabilities.

- Ts represents a set of Transaction simplification, with specified subsets formally described as:

$$
\mathrm{Ts}=\{\mathrm{Tsu}, \mathrm{Tsd}, \mathrm{Tsl}, \mathrm{Tss}\},
$$

where Tsu refers to User-interface friendliness, Tsd means Data available to user, Tsl shows Level of system integration, and Tss points at Supplier access to information.

- Vr contains a set of elements referred to Variance reduction, represented as follows:

$$
\mathrm{Vr}=\{\mathrm{Vrd}, \mathrm{Vrc}, \mathrm{Vrs}, \mathrm{Vri}\},
$$

where Vrd shows Demand forecasting tools, Vrc means Communication with customer/supplier, Vrs depicts Statistical process control, and Vri represents Internal system integration. 
- Iv represents a set of Inventory velocity, formally defined as follows:

$$
\mathrm{Iv}=\{\operatorname{Ive}, \operatorname{Ivj}, \operatorname{Ivf}, \operatorname{Ivd}\},
$$

where the subsets are noted using abbreviations: Ive—Efficient third party relationship, Ivj—Just in time support, Ivf-Flexible manufacturing operations, Ivd-Flexible distribution options.

- P refers to a set of Postponement, represented as follows:

$$
\mathrm{P}=\{\mathrm{Pm}, \mathrm{Pf}, \mathrm{Pr}\}
$$

where the following subsets are included: $\mathrm{Pm}-$ Modular product design, $\mathrm{Pf}-$ Flexible packaging design, $\mathrm{Pr}$-Retail/distribution site data.

- Ssr is a set of Shared/shifted risk, formally noted as:

$$
\text { Ssr }=\{\text { Ssrc, Ssro, Ssrs }\},
$$

where the subsets mean as follows: Ssrc-Creation of standards, Ssro-Outsourcing agreements, Ssrs-Supplier customization.

- Ce represents a set of Compatible with environment, formally defined as follows:

$$
\mathrm{Ce}=\{\mathrm{Cep}, \mathrm{Cet}, \mathrm{Ceg}, \mathrm{Ceq}, \mathrm{Cedv}, \mathrm{Cee}, \mathrm{Cec}, \mathrm{Cepr}, \mathrm{Cef}, \mathrm{Ced}, \mathrm{Cea}, \mathrm{Ceet}\},
$$

where the following subsets are included: Cep-Pollution control initiatives, Cet-The use of green technology and materials, Ceg-Participation in green projects, Ceq-Quality of Service, Cedv-Delivery, Cee-Environmental certification, Cec-Cooperating with green organization, Cepr-The profitability and financial position, Cef-Flexibility in the demand changes, Cea-Product life cycle assessment, Ceet-Employee training.

- $\mathrm{T}$ is defined as a set of Trust, formally defined as:

$$
\mathrm{T}=\{\mathrm{Tf}, \mathrm{Tt}\},
$$

where the following subsets are included: $\mathrm{Tf}$-Inter-firm trust, $\mathrm{Tt}$-Interpersonal trust.

- Mo represents a set of Management and organization, specified as follows:

$$
\text { Mo }=\{\text { Mor, Mod, Moe, Mot, Mof, Mop }\}
$$

where the subsets are formalized as follows: Mor-Responsiveness, Mod-Discipline, Moe-Environment, Mot—Technical capability, Mof-Facility and capacity, Mop-Performance history.

- Csd refers to a set of Capability of Supplier/Delivery, formalized in the form of:

$$
\text { Csd }=\{C s d t, C s d p, C s d e\},
$$

where the subsets are as follows: Csdt-Technological capability, Csdp—Production capability, Csde-Electronic transaction capability.

- Sc is defined as a set of Service capability, formally defined as:

$$
\mathrm{Sc}=\{\mathrm{Scf}, \mathrm{Sce}, \mathrm{Scp}, \mathrm{Scr}\},
$$

where the following subsets are included: Scf-Flexibility, Sce-Ease of communication, Scp-Production facility and capacity, Scr-Response to changes). 
- Pp represents a set of Pricing policy, with formal presentation presented below:

$$
\mathrm{Pp}=\{\mathrm{Ppf}, \mathrm{Ppq}, \mathrm{Ppp}, \mathrm{Ppt}\}
$$

where the following subsets are specified: Ppf-Fair price, Ppq-Quantity discount rate, Ppp-Price fluctuation, Ppt-Total price);

- Rs is defined as a set of Responsiveness and services, formally represented as:

$$
\text { Rs }=\{\text { Rsa, Rsw, Rsp, Rsm, Rsr }\}
$$

where the subsets refer to consecutive elements: Rsa-After sales service, Rsw-Warranty, Rsp—Packaging capacity, Rsm-Mutual trust and ease of communication, Rsr-Responsiveness and attitude.

- Fx represents a set of Flexibility, with formal presentation presented below:

$$
F x=\{\text { Fxp, Fxit, Fxt }\},
$$

where the subsets are defined as follows: Fxp—Having new production technology, Fxit—IT and automation usage, Fxt-Technical capacity.

- Tpc refers to a set of Technical and production capability, formalized in the form of:

$$
\mathrm{Tpc}=\{\mathrm{Tpcr}, \mathrm{Tp} p \mathrm{~T}, \mathrm{Tpcs}\},
$$

where Tpcr means R\&D rate, Tpcp refers to Process capability, and Tpcs poins at Supplier's technical level.

- Rc contains a set of Relation combination, formally defined as:

$$
\mathrm{Rc}=\{\mathrm{Rct}, \mathrm{Rcm}, \mathrm{Rcc}\}
$$

where the subsets are specified as follows: Rct-Technique cooperation, Rcm-Market cooperation, Rcc-Cooperative time.

- Om is defined as a set of Organizational management, formally defined as:

$$
\mathrm{Om}=\{\mathrm{Omi}, \mathrm{Ome}\}
$$

where the subsets are represented by the specified abbreviations: Omi-Inventory turnover ratio, Ome-Operating expense rate.

- Ee represents a set of Eco-efficiency, with formal presentation presented below:

$$
\text { Ee }=\{\text { Eegd, Eep, Eegi, Eegc, Eeem }\},
$$

where the subsets are defined as follows: Eegd-Green design, Eep-Pollution prevention, Eegi-Green image, Eegc—Green capability, Eeem-Environmental management system.

- Pr contains a set of Price, formally described as:

$$
\operatorname{Pr}=\{\text { Prp, Pre, Prpp, Prpv, Prt }\},
$$

where the subsets reflect the following elements: Prp-Price, Pre-The estimated price level offered by a supplier as compared to the average market price, Prpp—Purchasing price, Prpv—Price performance value, Prt-Transportation cost. 
- $\quad \mathrm{Ci}$ is defined as a set of Capacity/infrastructure, formally defined as:

$$
\mathrm{Ci}=\{\text { Cir, Cicr, Cicp, Cimw, Cimr, Cime, Cimf, Cit, Cii }\} \text {, }
$$

where the subsets are described as: Cir-Reserve capacity, Circ-Capacity usage ratio, Cipc-Production capacity of the client plant, Cimw-Maximum capacity per warehouse, Cimr-Maximum capacity per repair center, Cime-Maximum capacity of expansion per warehouse, Cimf-Maximum capacity of expansion per repair facility, Cit-Technical/Engineering Capability, Cii-Inability to meet future requirement.

- L represents a single element set of Location, defined as follows:

$$
\mathrm{L}=\{\mathrm{Lg}\}
$$

where $\mathrm{Lg}$ refers to Geographical location.

- Se is defined as a set of Socio-efficiency, formally defined as:

$$
\text { Se }=\{\text { Sel, Sec, Sea, Sep, Sei, See, Ser, Sed, Ses }\},
$$

where the subsets are described as: Sel—Long term relationship, Sec-Communication openness, Sea-Reciprocal arrangement, Sep-Physical facilities, Sei-Relationship intensity, See-Effort to establish cooperation, Ser-Reputation, Sed-Decrease customer response time, Ses-Increase employee's skills).

- $\mathrm{Km}$ is defined as a set of Knowledge management, with formal presentation as follows:

$$
\mathrm{Km}=\{\mathrm{Kmw}, \mathrm{Kmi}, \mathrm{Kme}, \mathrm{Kms}\} \text {, }
$$

where the subsets are noted as: $\mathrm{Kmw}$-Willingness to share information, $\mathrm{Kmi}$-Increase order information sharing, Kme-Expand accessibility of information, Kms-Information sharing.

- D contains a set of Delivery, formally described as:

$$
\begin{gathered}
\mathrm{D}=\{\mathrm{Dd}, \mathrm{Ddt}, \mathrm{Dq}, \text { Dot, Dp, Dt, Dds, Dcq, Dc, Ds, Dr, Dqs, Drq, Drr, Dl, Dod, Ddf, } \\
\text { Dse, Djt, Dotd, Dmp }\}
\end{gathered}
$$

where the subsets represent the following elements: Dd—Delivery, Ddt-Compliance delivery with due time, Dq-Compliance delivery with quantity, Dot-Delivery on time, Dp-Price, Dt-Transport, Dds-Conformance to delivery schedule, Dcq-Conformance to quantity, Dc-Choice of transportation, Ds-Supplier's delay on delivery, Dr-Defect rate (return rate), Dqs-Quality system certificate of the supplier, Drq-Reliability of quality, Drr-Rejection rate, Dl—Lead time, Dod-On-time delivery rate, Dlf-Delivery flexibility, Dse-Supplier's effort in promoting JIT principles, Dotd-On time delivery, Dmp-Measures the percentage of on-time delivery.

- Ds represents a set of Delivery schedule, defined formally as:

$$
\text { Ds }=\{\text { Dss, Dst, Dsd }\},
$$

where the subsets refer to the following elements: Dss—Shortest lead time, Dst-Delivery on time rate, Dsd-Serious delivery delay rate.

- Qp is defined as a separated set of Quality of the product, formalized as:

$$
\mathrm{Qp}=\{\mathrm{Qpi}, \mathrm{Qpp}, \mathrm{Qpy}\}
$$

where the subsets mean: Qpi-Ingredient consistency, Qpp—Process capability, Qpy—Yield rate. 
- Ocp covers a set of Overall cost of the product, formally noted as:

$$
\text { Ocp }=\{\text { Ocpr, Ocph, Ocpl }\},
$$

where the subsets refer to the following items: Ocpr—Recycled material price, Ocph-Handling cost, Ocpl-Process loss cost.

- Ec represents a set of Environmental collaboration, defined as follows:

$$
\mathrm{Ec}=\{\mathrm{Ect}, \mathrm{Ecg}\},
$$

where the subsets cover as follows: Ect-Technology for recycling products and process, Ecg-Green manufacturing policy.

- $\quad \mathrm{Cd}$ is defined as a separated set of Capability of Supplier/Delivery, formalized as:

$$
\mathrm{Cd}=\{\mathrm{Cdl}, \mathrm{Cds}, \mathrm{Cdt}, \mathrm{Cdpd}, \mathrm{Cdo}, \mathrm{Cdlt}, \mathrm{Cdr}, \mathrm{Cdtc}, \mathrm{Cdf}, \mathrm{Cdss}, \mathrm{Cdtf}, \mathrm{Cdsd}\},
$$

where the following subsets are included: Cdl—Logistic capabilities, Cds-Supplying capability, Cdt-Level of Technique, Cdpd-Capability of Product Development, Cdo-Order fulfil rate, Cdlt-Lead time, Cdr-Capability of R\&D, Cdtc-Technology Level, Cdf-Flexibility of the Supplier, Cdss-Supplier Stock Management, Cdtf-Technical capability and facility, Cdsd-Service and delivery.

- Po represents a subsequent set of Production, defined as follows:

$$
\text { Po }=\{\text { Pol, Pob, Poi }\},
$$

where the subsets point at specifically: Pol—Product line, Pob—Product bundle, Poi-Improve production efficiency.

- Ms is defined as a separated set of Market strategy, formalized as:

$$
\mathrm{Ms}=\{\mathrm{Msc}, \mathrm{Mse}, \mathrm{Msa}, \mathrm{Msi}\},
$$

where the subsets cover: Msc-Market coverage, Mse-Marketing experience, Msa-Management ability, Msi-Identify market innovative opportunities.

- $\quad B i$ is a separated set of Business improvement, formalized in the form of:

$$
\mathrm{Bi}=\{\text { Bir, Bif, Bim, Bio }\},
$$

where Bir means Reputation of industry, Bif refers to Financial strength, Bim presents Managing ability, and Bio points at Organizations customers.

- Ef represents a subsequent set of Extend of fitness, defined as follows:

$$
E f=\{E f s, E f f, E f d\}
$$

where the subsets are as follows: Efs-Sharing of expertise, Eff-Flexible practices, Efd-Diversified customers.

- Qt represents a single element set of Quantity, formalized as:

$$
\mathrm{Qt}=\{\mathrm{Qtq}\}
$$

where Qtq refers to Quantity. 
- L is a separated set of Logistics, formalized in the form of:

$$
\mathrm{L}=\{\mathrm{Lw}, \mathrm{Lt}, \mathrm{Lit}, \mathrm{Ltd} ., \mathrm{Lcf}, \mathrm{Lsq}, \mathrm{Lto}, \mathrm{Lsf}, \mathrm{Litl}, \mathrm{Lim}, \mathrm{Lr}, \mathrm{Ld}, \mathrm{Lrf}, \mathrm{Lrr}, \mathrm{Lp}\},
$$

where the subsets cover the following items: Lw-Warehouse management, Lt-Transportation management, Lit-IT management, Ltd.-On time delivery ratio, Lcf-Confirmed fill rate, Lsq-Service quality level, Lto-Total order cycle time, Lsf-System flexibility index, Litl-Integration technologies level, Lim-Increment in market share, Lr-Research and development ratio, Ld-Demand forecast for each client, product, Lrf-Return forecast for each client, product, Lrr-Rejection rate, Lp-Procurement.

- Va represents a subsequent set of Value added services to customers, defined as follows:

$$
\text { Va }=\{\text { Vac, Vas, Vag, Vacs, Vaar, Varr, Varm, Varf, Vad, Vacc, Vaas, Vam }\},
$$

where the subsets cover as follows: Vac-Convenience, Vas-Customer service, Vag-Green products, Vacs-Customer satisfaction, Vaar-Assembly/reassembly, Varr-Repackaging/re-labeling, Varm—Remanufacturing, Varf-Refurbishment, Vad—Disposal, Vacc-Call-center operation, Vaas-After sales service, Vam-Management/performance reports.

- As is a separated set of Alliances with suppliers, defined in the form of:

$$
\text { As }=\{\text { Asc, Asm, Asf, Ask }\}
$$

where the following subsets are included: Asc-Competitiveness, Asm-Mentoring of suppliers, Asf-Formation of strategic alliances, Ask-Knowledge management.

- Ev represents a single element set of Environmental, formalized as:

$$
\mathrm{Ev}=\{\mathrm{Evp}\},
$$

where Evp refers to Product recovery options and green products.

- Ppr is a separated set of Process and product quality, defined as:

$$
\text { Ppq }=\{\text { Ppqn, Ppqc, Ppqt }\}
$$

where the subsets cover the elements as: Ppqn-Non defect rate, Ppqc-Corrective actions, Ppqt-Throughput time.

- Mi represents a subsequent set of Management and innovation, defined as follows:

$$
\mathrm{Mi}=\{\text { Mih, Mir, Mid }\}
$$

where the subsets include the items as follows: Mih—Human Resources, Mir-Relationships with large enterprises, Mid-R\&D investment.

- Fp is defined as a set of Financial position, formally noted as:

$$
\mathrm{Fp}=\{\mathrm{Fpp}, \mathrm{Fpa}, \mathrm{Fpl}\},
$$

where Fpp means to Profit margin, Fpa refers to Assets, and Fpl presents Liquidity.

- Cp represents a single element set of Capacity, formalized as:

$$
\mathrm{Cp}=\{\mathrm{Cppc}\}
$$

where Cppc presents Production capacity. 
- Tr presents a single element set of Transport, formalized as:

$$
\operatorname{Tr}=\{\text { Tre }\},
$$

where Tre refers to Enhance transportation tool utilization.

- Epm is defined as a set of Environment protection/Environment management, formally noted as:

$$
\text { Epm }=\{\text { Epms, Epme, Epmu, Epmh, Epmp }\}
$$

where the subsets are defined as: Epms-Environment protection system certification, Epme-Environment efficiency, Epmu-EUP, Epmh—RoHS, Epmp-Environmental protection policies/plans.

- Csr is a separated set of Corporate social responsibility, formalized as follows:

$$
\text { Csr }=\{\text { Csri, Csrs, Csrd, Csrr }\}
$$

where the subsets include the following items: Csri-The interests and rights of employee, Csrs-The rights of stakeholder, Csrd-Information disclosure, Csrr-Respect for the policy.

- Pc is defined as a set of Pollution control, represented in the form of:

$$
\text { Pc }=\{\text { Pca, Pcw, Pcpi, Pcpr }\},
$$

where the subsets cover as follows: Pca-Air Emissions, Pcw—Waste water, Pcpi-Pollution control Initiatives, Pcpr-Pollution reduction capability.

- Gp is a separated set of Green Product, formalized as:

$$
\mathrm{Gp}=\{\mathrm{Gpr}, \mathrm{Gpp}, \mathrm{Gpc}, \mathrm{Gpg}, \mathrm{Gpgp}, \mathrm{Gpr}, \mathrm{Gpm}, \mathrm{Gpd}\},
$$

where the subsets refer to: Gpr-Recycle, Gpp-Green packaging, Gpc-Cost of component disposal, Gpg-Green certifications, Gpgp-Green production, Gpr-Reuse, Gpm-Re-Manufacture, Gpd-Disposal.

- Gi refers to a set of Green Image, formalized as:

$$
\text { Gi }=\{\text { Gim, Gia, Gir, Gic, Gisr, Gimc }\},
$$

where the subsets include: Gim-Materials used in the supplied components that reduce the impact on natural resources, Gia-Ability to alter process and product for reducing the impact on natural resources, Gir-Ratio of green customers to total customers, Gic-Green customers' market share, Gisr-Stakeholder's relationship, Gimc-Green materials coding and recording.

- Gin is a separated set of Green Innovation, defined as follows:

$$
\text { Gin }=\{\text { Gint, Gind, Ginp, Ginr, Ginrp, Ginrd, Ginre }\} \text {, }
$$

where the subsets reflect to: Gint-Green Technology Capabilities, Gind-Green design, Ginp-Green process/Production planning, Ginr-Recycling product design, Ginrp—Renewable product design, Ginrd-Green R\&D project, Ginre-Redesign of product.

- Hms represent a subsequent set of Hazardous Substance Management, formalized as follows:

$$
\text { Hms }=\{\text { Hsmm, Hsmp, Hsma, Hsmw, Hsmi }\},
$$


where the subsets are defined as follows: Hsmm-Management for hazardous substances, Hsmp-Prevention of mixed material, Hsma-Process auditing, Hsmw—Warehouse management, Hsmi-Inventory of hazardous substances.

- Cmp is a single set of Compatibility, defined as follows:

$$
\mathrm{Cmp}=\{\mathrm{Cmpc}\}
$$

where Cmpc refers to Compatibility.

- $\mathrm{Rp}$ is a single set of Reputation, formalized as follows:

$$
\operatorname{Rp}=\{\text { Rpr }\}
$$

where Rpr denotes Reputation.

- Ltr is a single set of Long-term relationships, presented formally as:

$$
\operatorname{Ltr}=\{\mathrm{Ltrr}\},
$$

where Ltrr means Long-term relationships.

- $\quad$ Fpr is a single set of Financial performance, presented below as:

$$
\text { Fpr }=\{\text { Fprf }\},
$$

where Fprf points at Financial performance.

- $\mathrm{Rm}$ is a single set of Risk management, formalized as:

$$
\mathrm{Rm}=\{\mathrm{Rmrm}\},
$$

where Rmrm refers to Risk management.

- Pm is a single set of Performance measurement, defined as:

$$
\mathrm{Pm}=\{\mathrm{Pmpm}\}
$$

where Pmpm points at Performance measurement.

- Wlm is a single set of Willingness to use logistics manpower, described formally as:

$$
\mathrm{Wlm}=\{\mathrm{Wlml}\},
$$

where Wlml covers Willingness to use logistics manpower.

- Flexibility in billing and payment;

$$
\mathrm{Fbp}=\{\mathrm{Fbpf}\},
$$

where Fbpf refers to Flexibility in billing and payment.

- Qm is a single set of Quality of management, presented below in the form of:

$$
\mathrm{Qm}=\{\mathrm{Qmq}\},
$$

where Qmq refers to Quality of management.

- $\mathrm{Sv}$ is a single set of Supply variety, formalized as:

$$
\mathrm{Sv}=\{\mathrm{Svn}\},
$$

where Svn codes Number of parts supplied by the supplier. 
- $\quad \mathrm{D}$ is a single set of Distance, formally defined as:

$$
\mathrm{D}=\{\text { Dde }\}
$$

where Dde presents The distance is related to delivery efficiency.

\section{References}

1. Akman, G. Evaluating suppliers to include green supplier development programs via fuzzy c-means and VIKOR methods. Comput. Ind. Eng. 2015, 86, 69-82. [CrossRef]

2. Nielsen, I.E.; Banaeian, N.; Golińska, P.; Mobli, H.; Omid, M. Green Supplier Selection Criteria: From a Literature Review to a Flexible Framework for Determination of Suitable Criteria. In Logistics Operations, Supply Chain Management and Sustainability; Golinska, P., Ed.; Springer International Publishing: Cham, Switzerland, 2014; pp. 79-99. ISBN 978-3-319-07286-9.

3. Ng, W.L. An efficient and simple model for multiple criteria supplier selection problem. Eur. J. Oper. Res. 2008, 186, 1059-1067. [CrossRef]

4. Chan, F.T.S.; Kumar, N. Global supplier development considering risk factors using fuzzy extended AHP-based approach. Omega 2007, 35, 417-431. [CrossRef]

5. de Boer, L.; Labro, E.; Morlacchi, P. A review of methods supporting supplier selection. Eur. J. Purch. Supply Manag. 2001, 7, 75-89. [CrossRef]

6. Gurel, O.; Acar, A.Z.; Onden, I.; Gumus, I. Determinants of the Green Supplier Selection. Procedia Soc. Behav. Sci. 2015, 181, 131-139. [CrossRef]

7. Min, S.; Mentzer, J.T. Developing and Measuring Supply Chain Management Concepts. J. Bus. Logist. 2004, 25, 63-99. [CrossRef]

8. Chan, F.T.S.; Kumar, N.; Tiwari, M.K.; Lau, H.C.W.; Choy, K.L. Global supplier selection: A fuzzy-AHP approach. Int. J. Prod. Res. 2008, 46, 3825-3857. [CrossRef]

9. Kuo, R.J.; Wang, Y.C.; Tien, F.C. Integration of artificial neural network and MADA methods for green supplier selection. J. Clean. Prod. 2010, 18, 1161-1170. [CrossRef]

10. Lee, A.H.I.; Kang, H.Y.; Hsu, C.F.; Hung, H.C. A green supplier selection model for high-tech industry. Expert Syst. Appl. 2009, 36, 7917-7927. [CrossRef]

11. Sancha, C.; Gimenez, C.; Sierra, V. Achieving a socially responsible supply chain through assessment and collaboration. J. Clean. Prod. 2016, 112, 1934-1947. [CrossRef]

12. Shaw, K.; Shankar, R.; Yadav, S.S.; Thakur, L.S. Global supplier selection considering sustainability and carbon footprint issue: AHP multi-objective fuzzy linear programming approach. Int. J. Oper. Res. 2013, 17, 215-247. [CrossRef]

13. Moher, D.; Liberati, A.; Tetzlaff, J.; Altman, D.G. The PRISMA Group Preferred Reporting Items for Systematic Reviews and Meta-Analyses: The PRISMA Statement. PLoS Med. 2009, 6, e1000097. [CrossRef] [PubMed]

14. Smith, B. Ontology (Science); IOS Press: Amsterdam, The Netherlands, 2008; pp. 21-35.

15. Luciano, F. (Ed.) Blackwell Guide to the Philosophy of Computing and Information; Blackwell: Oxford, UK, 2003; pp. $155-166$.

16. Obrst, L. Ontologies for semantically interoperable systems. In Proceedings of the twelfth International Conference on Information and Knowledge Management-CIKM '03, New Orleans, LA, USA, 3-8 November 2003; ACM Press: New York, NY, USA, 2003; p. 366.

17. Fox, M.S.; Grüninger, M. Ontologies for Enterprise Modelling. In Enterprise Engineering and Integration; Kosanke, K., Nell, J.G., Eds.; Springer: Berlin/Heidelberg, Germany, 1997; pp. 190-200. ISBN 978-3-540-63402-7.

18. Lee, C.H.; Wang, Y.H.; Trappey, A.J.C. Ontology-based reasoning for the intelligent handling of customer complaints. Comput. Ind. Eng. 2015, 84, 144-155. [CrossRef]

19. Chu, C.C.; Cheng, Y.F.; Tsai, F.S.; Tsai, S.B.; Lu, K.H. Open Innovation in Crowdfunding Context: Diversity, Knowledge, and Networks. Sustainability 2019, 11, 180. [CrossRef]

20. Maedche, A.; Staab, S. Ontology learning for the Semantic Web. IEEE Intell. Syst. 2001, 16, 72-79. [CrossRef] 
21. Mankovskii, S.; Gogolla, M.; Urban, S.D.; Dietrich, S.W.; Urban, S.D.; Dietrich, S.W.; Yang, M.H.; Dobbie, G.; Ling, T.W.; Halpin, T.; et al. Ontology. In Encyclopedia of Database Systems; Liu, L., Özsu, M.T., Eds.; Springer: Boston, MA, USA, 2009; pp. 1963-1965. ISBN 978-0-387-35544-3.

22. Wang, S.; Noe, R.A. Knowledge sharing: A review and directions for future research. Hum. Resour. Manag. Rev. 2010, 20, 115-131. [CrossRef]

23. Kanter, J. Knowledge Management, Practically Speaking. Inf. Syst. Manag. 1999, 16, 7-15. [CrossRef]

24. Uschold, M. Knowledge level modelling: Concepts and terminology. Knowl. Eng. Rev. 1998, 13, 5-29. [CrossRef]

25. Gruber, T. Ontology; Springer: Berlin/Heidelberg, Germany, 2009; ISBN 0-387-35544-8.

26. Dhaouadi, R.; Benmiled, A.; Ghédira, K. Ontology based Multi Agent System for Improved Procurement Process: Application for the Handicraft Domain. Procedia Comput. Sci. 2014, 35, 251-260. [CrossRef]

27. Konys, A. An Ontology-Based Knowledge Modelling for a Sustainability Assessment Domain. Sustainability 2018, 10, 300. [CrossRef]

28. Fensel, D.; McGuiness, D.L.; Schulten, E.; Ng Keong, W.; Lim, G.P.; Yan, G.H. Ontologies and electronic commerce. IEEE Intell. Syst. 2001, 16, 8-14. [CrossRef]

29. Corrente, S.; Greco, S.; Słowiński, R. Multiple Criteria Hierarchy Process with ELECTRE and PROMETHEE. Omega 2013, 41, 820-846. [CrossRef]

30. Corso, M.; Dogan, S.F.; Mogre, R.; Perego, A. The role of knowledge management in supply chains: Evidence from the Italian food industry. Int. J. Netw. Virtual Organ. 2010, 7, 163-183. [CrossRef]

31. Smith, B. FOIS introduction: Ontology-Towards a new synthesis. In Proceedings of the international conference on Formal Ontology in Information Systems-FOIS '01, Ogunquit, ME, USA, 17-19 October 2001.

32. Gene Ontology Consortium. The Gene Ontology (GO) database and informatics resource. Nucleic Acids Res. 2004, 32, 258-261. [CrossRef]

33. Konys, A. A Framework for Analysis of Ontology-Based Data Access. In Computational Collective Intelligence; Nguyen, N.T., Iliadis, L., Manolopoulos, Y., Trawiński, B., Eds.; Springer International Publishing: Cham, Switzerland, 2016; Volume 9876, pp. 397-408. ISBN 978-3-319-45245-6.

34. Cai, M.; Zhang, W.Y.; Zhang, K. ManuHub: A Semantic Web System for Ontology-Based Service Management in Distributed Manufacturing Environments. IEEE Trans. Syst. Man Cybern. Part Syst. Hum. 2011, 41, 574-582. [CrossRef]

35. Lin, H. Knowledge sharing and firm innovation capability: An empirical study. Int. J. Manpow. 2007, 28, 315-332. [CrossRef]

36. Wu, I.L.; Chen, J.L. Knowledge management driven firm performance: The roles of business process capabilities and organizational learning. J. Knowl. Manag. 2014, 18, 1141-1164. [CrossRef]

37. Cruz, J.M.; Matsypura, D. Supply chain networks with corporate social responsibility through integrated environmental decision-making. Int. J. Prod. Res. 2009, 47, 621-648. [CrossRef]

38. Young, A. Sustainable Supply Network Management. Corp. Environ. Strategy 2001, 8, 260-268. [CrossRef]

39. Kovács, G. Corporate environmental responsibility in the supply chain. J. Clean. Prod. 2008, 16, 1571-1578. [CrossRef]

40. Sharfman, M.P.; Shaft, T.M.; Anex, R.P. The road to cooperative supply-chain environmental management: Trust and uncertainty among pro-active firms. Bus. Strategy Environ. 2009, 18, 1-13. [CrossRef]

41. Min, H.; Galle, W.P. Green Purchasing Strategies: Trends and Implications. Int. J. Purch. Mater. Manag. 1997, 33, 10-17. [CrossRef]

42. Günther, E.; Scheibe, L. The hurdle analysis. A self-evaluation tool for municipalities to identify, analyse and overcome hurdles to green procurement. Corp. Soc. Responsib. Environ. Manag. 2006, 13, 61-77. [CrossRef]

43. Carter, C.R. Purchasing social responsibility and firm performance: The key mediating roles of organizational learning and supplier performance. Int. J. Phys. Distrib. Logist. Manag. 2005, 35, 177-194. [CrossRef]

44. Zsidisin, G.A.; Siferd, S.P. Environmental purchasing: A framework for theory development. Eur. J. Purch. Supply Manag. 2001, 7, 61-73. [CrossRef]

45. González-Benito, J.; González-Benito, Ó. The role of stakeholder pressure and managerial values in the implementation of environmental logistics practices. Int. J. Prod. Res. 2006, 44, 1353-1373. [CrossRef]

46. Linton, J.D.; Klassen, R.; Jayaraman, V. Sustainable supply chains: An introduction. J. Oper. Manag. 2007, 25, 1075-1082. [CrossRef] 
47. Bai, C.; Sarkis, J. Integrating sustainability into supplier selection with grey system and rough set methodologies. Int. J. Prod. Econ. 2010, 124, 252-264. [CrossRef]

48. Erkman, S. Industrial ecology: An historical view. J. Clean. Prod. 1997, 5, 1-10. [CrossRef]

49. Jelinski, L.W.; Graedel, T.E.; Laudise, R.A.; McCall, D.W.; Patel, C.K. Industrial ecology: Concepts and approaches. Proc. Natl. Acad. Sci. USA 1992, 89, 793-797. [CrossRef]

50. Bhote, K.R. Strategic Supply Management: A Blueprint for Revitalizing the Manufacturer-Supplier Partnership; American Management Association: New York, NY, USA, 1989; ISBN 978-0-8144-5925-6.

51. Kraljic, P. Purchasing must become supply management. Harv. Bus. Rev. 1983, 61, 109-117.

52. Gelderman, C.J.; van Weele, A.J. Purchasing Portfolio Models: A Critique and Update. J. Supply Chain Manag. 2005, 41, 19-28. [CrossRef]

53. Gungor, A.; Gupta, S.M. Issues in environmentally conscious manufacturing and product recovery: A survey. Comput. Ind. Eng. 1999, 36, 811-853. [CrossRef]

54. Bras, B.; McIntosh, M.W. Product, process, and organizational design for remanufacture-An overview of research. Robot. Comput. Integr. Manuf. 1999, 15, 167-178. [CrossRef]

55. Fleischmann, M.; Krikke, H.R.; Dekker, R.; Flapper, S.D.P. A characterisation of logistics networks for product recovery. Omega 2000, 28, 653-666. [CrossRef]

56. Jayaraman, V.; Patterson, R.A.; Rolland, E. The design of reverse distribution networks: Models and solution procedures. Eur. J. Oper. Res. 2003, 150, 128-149. [CrossRef]

57. Beamon, B.M. Measuring supply chain performance. Int. J. Oper. Prod. Manag. 1999, 19, 275-292. [CrossRef]

58. Rezaei, J.; Ortt, R. A multi-variable approach to supplier segmentation. Int. J. Prod. Res. 2012, 50, $4593-4611$. [CrossRef]

59. Segura, M.; Maroto, C. A multiple criteria supplier segmentation using outranking and value function methods. Expert Syst. Appl. 2017, 69, 87-100. [CrossRef]

60. Rezaei, J.; Ortt, R. Multi-criteria supplier segmentation using a fuzzy preference relations based AHP. Eur. J. Oper. Res. 2013, 225, 75-84. [CrossRef]

61. Day, M.; Magnan, G.M.; Moeller, M.M. Evaluating the bases of supplier segmentation: A review and taxonomy. Ind. Mark. Manag. 2010, 39, 625-639. [CrossRef]

62. Ip, W.H.; Huang, M.; Yung, K.L.; Wang, D. Genetic algorithm solution for a risk-based partner selection problem in a virtual enterprise. Comput. Oper. Res. 2003, 30, 213-231. [CrossRef]

63. Virolainen, V.M. A survey of procurement strategy development in industrial companies. Int. J. Prod. Econ. 1998, 56-57, 677-688. [CrossRef]

64. Wątróbski, J.; Jankowski, J.; Ziemba, P.; Karczmarczyk, A.; Zioło, M. Generalised framework for multi-criteria method selection. Omega 2019, 86, 107-124. [CrossRef]

65. Govindan, K.; Khodaverdi, R.; Jafarian, A. A fuzzy multi criteria approach for measuring sustainability performance of a supplier based on triple bottom line approach. J. Clean. Prod. 2013, 47, 345-354. [CrossRef]

66. Chai, J.; Liu, J.N.K.; Ngai, E.W.T. Application of decision-making techniques in supplier selection: A systematic review of literature. Expert Syst. Appl. 2013, 40, 3872-3885. [CrossRef]

67. Lee, D.M.; Drake, P.R. A portfolio model for component purchasing strategy and the case study of two South Korean elevator manufacturers. Int. J. Prod. Res. 2010, 48, 6651-6682. [CrossRef]

68. Huang, G.Q.; Mak, K.L. WeBid: A web-based framework to support early supplier involvement in new product development. Robot. Comput. Integr. Manuf. 2000, 16, 169-179. [CrossRef]

69. Opricovic, S.; Tzeng, G.H. Compromise solution by MCDM methods: A comparative analysis of VIKOR and TOPSIS. Eur. J. Oper. Res. 2004, 156, 445-455. [CrossRef]

70. Rezaei, J.; Wang, J.; Tavasszy, L. Linking supplier development to supplier segmentation using Best Worst Method. Expert Syst. Appl. 2015, 42, 9152-9164. [CrossRef]

71. Chang, B.; Chang, C.W.; Wu, C.H. Fuzzy DEMATEL method for developing supplier selection criteria. Expert Syst. Appl. 2011, 38, 1850-1858. [CrossRef]

72. Ameri, F.; Dutta, D. A Matchmaking Methodology for Supply Chain Deployment in Distributed Manufacturing Environments. J. Comput. Inf. Sci. Eng. 2008, 8, 011002. [CrossRef]

73. Yang, D.; Dong, M.; Miao, R. Development of a product configuration system with an ontology-based approach. Comput. Aided Des. 2008, 40, 863-878. [CrossRef] 
74. Jang, J.; Jeong, B.; Kulvatunyou, B.; Chang, J.; Cho, H. Discovering and integrating distributed manufacturing services with semantic manufacturing capability profiles. Int. J. Comput. Integr. Manuf. 2008, 21, 631-646. [CrossRef]

75. Lee, J.; Jung, K.; Kim, B.H.; Peng, Y.; Cho, H. Semantic web-based supplier discovery system for building a long-term supply chain. Int. J. Comput. Integr. Manuf. 2015, 28, 155-169. [CrossRef]

76. Camarinha-Matos, L.M.; Cardoso, T. Selection of Partners for a Virtual Enterprise. In Infrastructures for Virtual Enterprises; Camarinha-Matos, L.M., Afsarmanesh, H., Eds.; Springer: Boston, MA, USA, 1999; Volume 27, pp. 259-278. ISBN 978-1-4757-5499-5.

77. Baldo, F.; Rabelo, R.J.; Vallejos, R.V. An Ontology-Based Approach for Selecting Performance Indicators for Partners Suggestion. In Establishing the Foundation of Collaborative Networks; Camarinha-Matos, L.M., Afsarmanesh, H., Novais, P., Analide, C., Eds.; Springer: Boston, MA, USA, 2007; pp. 187-196. ISBN 978-1-4757-0564-5.

78. Baldo, F.; Rabelo, R.J.; Vallejos, R.V. Modeling Performance Indicators' Selection Process For Vo Partners' Suggestions. In Innovation in Manufacturing Networks; Azevedo, A., Ed.; Springer: Boston, MA, USA, 2008; Volume 266, pp. 67-76. ISBN 978-0-387-09491-5.

79. Chen, Y.J. Structured methodology for supplier selection and evaluation in a supply chain. Inf. Sci. 2011, 181, 1651-1670. [CrossRef]

80. Karczmarczyk, A.; Jankowski, J.; Wątróbski, J. Multi-criteria decision support for planning and evaluation of performance of viral marketing campaigns in social networks. PLoS ONE 2018, 13, e0209372. [CrossRef]

81. Dickson, G.W. An Analysis of Vendor Selection Systems And Decisions. J. Purch. 1966, 2, 5-17. [CrossRef]

82. Weber, C.A.; Current, J.R.; Benton, W.C. Vendor selection criteria and methods. Eur. J. Oper. Res. 1991, 50, 2-18. [CrossRef]

83. Cheraghi, S.H.; Dadashzadeh, M.; Subramanian, M. Critical Success Factors For Supplier Selection: An Update. J. Appl. Bus. Res. JABR 2011, 20, 91-108. [CrossRef]

84. Thiruchelvam, S.; Tookey, J.E. Evolving Trends of Supplier Selection Criteria and Methods. Int. J. Automot. Mech. Eng. 2011, 4, 437-454. [CrossRef]

85. Irani, Z.; Kamal, M.M.; Sharif, A.; Love, P.E. Enabling sustainable energy futures: Factors influencing green supply chain collaboration. Prod. Plan. Control 2017, 28, 684-705. [CrossRef]

86. Luo, X.; Wu, C.; Rosenberg, D.; Barnes, D. Supplier selection in agile supply chains: An information-processing model and an illustration. J. Purch. Supply Manag. 2009, 15, 249-262. [CrossRef]

87. Fernie, J.; Fernie, S.; Moore, C.M. Principles of Retailing, 2nd ed.; Routledge: Abington Thames, UK, 2015; ISBN 978-1-315-76243-2.

88. Cheng, J.; Yeh, C.; Tu, C. Trust and knowledge sharing in green supply chains. Supply Chain Manag. Int. J. 2008, 13, 283-295. [CrossRef]

89. Sharif, A.M.; Irani, Z. Supply Chain Leadership. Int. J. Prod. Econ. 2012, 140, 57-68. [CrossRef]

90. Sodhi, M.S.; Son, B.G. Supply-chain partnership performance. Transp. Res. Part E Logist. Transp. Rev. 2009, 45, 937-945. [CrossRef]

91. Qian Li, Z.; Chen Tan, H.; Anumba, C.; Choy Chia, F. Development of a web-based system for managing suppliers' performance and knowledge sharing in construction project. Built Environ. Proj. Asset Manag. 2017, 7, 117-129. [CrossRef]

92. Jankowski, J.; Hamari, J.; Watróbski, J. A gradual approach for maximising user conversion without compromising experience with high visual intensity website elements. Internet Res. 2019, 29, 194-217. [CrossRef]

93. Konys, A. Knowledge-Based Approach to Question Answering System Selection. In Computational Collective Intelligence; Núñez, M., Nguyen, N.T., Camacho, D., Trawiński, B., Eds.; Springer International Publishing: Cham, Switzerland, 2015; Volume 9329, pp. 361-370. ISBN 978-3-319-24068-8.

94. Hashim, K.F.; Tan, F.B. The mediating role of trust and commitment on members' continuous knowledge sharing intention: A commitment-trust theory perspective. Int. J. Inf. Manag. 2015, 35, 145-151. [CrossRef]

95. Desouza, K.C.; Chattaraj, A.; Kraft, G. Supply chain perspectives to knowledge management: Research propositions. J. Knowl. Manag. 2003, 7, 129-138. [CrossRef]

96. Desouza, K.; Evaristo, R. Global Knowledge Management Strategies. Eur. Manag. J. 2003, 21, 62-67. [CrossRef] 
97. Kazemargi, N.; Cerruti, C.; Appolloni, A. Adopting open innovation in supply networks. Int. J. Manag. Enterp. Dev. 2016, 15, 174-190. [CrossRef]

98. Giannakis, M. Facilitating learning and knowledge transfer through supplier development. Supply Chain Manag. Int. J. 2008, 13, 62-72. [CrossRef]

99. Chong, A.Y.L.; Chan, F.T.; Goh, M.; Tiwari, M.K. Do interorganisational relationships and knowledge-management practices enhance collaborative commerce adoption? Int. J. Prod. Res. 2013, 51, 2006-2018. [CrossRef]

100. Zahay, D.L.; Handfield, R.B. The role of learning and technical capabilities in predicting adoption of B2B technologies. Ind. Mark. Manag. 2004, 33, 627-641. [CrossRef]

101. Mentzas, G.; Apostolou, D.; Kafentzis, K.; Georgolios, P. Inter-organizational networks for knowledge sharing and trading. Inf. Technol. Manag. 2006, 7, 259-276. [CrossRef]

102. Arslan, G.; Kivrak, S.; Birgonul, M.T.; Dikmen, I. Improving sub-contractor selection process in construction projects: Web-based sub-contractor evaluation system (WEBSES). Autom. Constr. 2008, 17, 480-488. [CrossRef]

103. Desai, A.; Rai, S. Knowledge Management for Downstream Supply Chain Management of Indian Public Sector Oil Companies. Procedia Comput. Sci. 2016, 79, 1021-1028. [CrossRef]

104. Rodríguez-Enríquez, C.A.; Alor-Hernández, G.; Mejia-Miranda, J.; Sánchez-Cervantes, J.L.; Rodríguez-Mazahua, L.; Sánchez-Ramírez, C. Supply chain knowledge management supported by a simple knowledge organization system. Electron. Commer. Res. Appl. 2016, 19, 1-18. [CrossRef]

105. Wu, Y.C.; Goh, M.; Yuan, C.H.; Huang, S.H. Logistics management research collaboration in Asia. Int. J. Logist. Manag. 2017, 28, 206-223. [CrossRef]

106. Mollahosseini, A.; Barkhordar, M. Supplier Knowledge Management For Supplier Development. Rev. Bus. Inf. Syst. RBIS 2010, 14, 17-25. [CrossRef]

107. Stock, J.R.; Boyer, S.L.; Harmon, T. Research opportunities in supply chain management. J. Acad. Mark. Sci. 2010, 38, 32-41. [CrossRef]

108. Ang, C.L.; Gay, R.; Sourina, O. Data integration for virtual enterprise in cyberworlds. In Proceedings of the 2005 International Conference on Cyberworlds (CW'05), Singapore, 23-25 November 2005.

109. Maamar, Z.; Faci, N.; Mostéfaoui, S.K.; Akhter, F. Towards a Framework for Weaving Social Networks Into Mobile Commerce. Int. J. Syst. Serv. Oriented Eng. 2011, 2, 32-46. [CrossRef]

110. Lee, S.; Choi, K.; Suh, Y. A personalized trustworthy seller recommendation in an open market. Expert Syst. Appl. 2013, 40, 1352-1357. [CrossRef]

111. Chen, C.T.; Lin, C.T.; Huang, S.F. A fuzzy approach for supplier evaluation and selection in supply chain management. Int. J. Prod. Econ. 2006, 102, 289-301. [CrossRef]

112. Chen, C.T. Extensions of the TOPSIS for group decision-making under fuzzy environment. Fuzzy Sets Syst. 2000, 114, 1-9. [CrossRef]

113. Roszkowska, E.; Wachowicz, T. Metoda Topsis i Jej Rozszerzenia-Studium Metodologiczne; University of Economics in Katowice: Katowice, Poland, 2013; pp. 11-40.

114. Grzegorzewski, P.; Mrówka, E. Trapezoidal approximations of fuzzy numbers-Revisited. Fuzzy Sets Syst. 2007, 158, 757-768. [CrossRef]

115. Ban, A. Approximation of fuzzy numbers by trapezoidal fuzzy numbers preserving the expected interval. Fuzzy Sets Syst. 2008, 159, 1327-1344. [CrossRef]

116. Abbasbandy, S.; Amirfakhrian, M. The nearest trapezoidal form of a generalized left right fuzzy number. Int. J. Approx. Reason. 2006, 43, 166-178. [CrossRef]

117. Khodaverdi, R.; Olfat, L. A fuzzy MCDM approach for supplier selection and evaluation: A case study in an automobile manufacturing company. In Proceedings of the 2011 IEEE International Conference on Industrial Engineering and Engineering Management, Singapore, 6-9 December 2011.

118. Palanisamy, P.; Abdul Zubar, H. Hybrid MCDM approach for vendor ranking. J. Manuf. Technol. Manag. 2013, 24, 905-928. [CrossRef]

119. de Boer, L.; van der Wegen, L.; Telgen, J. Outranking methods in support of supplier selection. Eur. J. Purch. Supply Manag. 1998, 4, 109-118. [CrossRef]

120. Shyur, H.J.; Shih, H.S. A hybrid MCDM model for strategic vendor selection. Math. Comput. Model. 2006, 44, 749-761. [CrossRef] 
121. Gencer, C.; Gürpinar, D. Analytic network process in supplier selection: A case study in an electronic firm. Appl. Math. Model. 2007, 31, 2475-2486. [CrossRef]

122. Tam, M.C.Y.; Tummala, V.M.R. An application of the AHP in vendor selection of a telecommunications system. Omega 2001, 29, 171-182. [CrossRef]

123. Malmir, R.; Hamzehi, E.; Farsijani, H. A Multi Stage Decision Making Model to Evaluate Suppliers by Using MOLP and ANP in a Strategic Approach. Int. J. Appl. Innov. Eng. Manag. 2013, 2, 563-577.

124. Meade, L.; Sarkis, J. Strategic analysis of logistics and supply chain management systems using the analytical network process. Transp. Res. Part E Logist. Transp. Rev. 1998, 34, 201-215. [CrossRef]

125. Shemshadi, A.; Toreihi, M.; Shirazi, H.; Tarokh, M.J. Supplier selection based on supplier risk: An ANP and fuzzy TOPSIS approach. J. Math. Comput. Sci. 2011, 2, 111-121. [CrossRef]

126. Dehghani, M.; Esmaeilian, M.; Tavakkoli-Moghaddam, R. Employing fuzzy ANP for green supplier selection and order allocations: A case study. Int. J. Econ. Manag. Soc. Sci. 2013, 2, 565-575.

127. Tahriri, F.; Osman, M.R.; Ali, A.; Yusuff, R.; Esfandiary, A. AHP approach for supplier evaluation and selection in a steel manufacturing company. J. Ind. Eng. Manag. 2008, 1, 54-76.

128. Pani, A.K.; Kar, A.K. A Study to Compare Relative Importance of Criteria for Supplier Evaluation in e-Procurement. In Proceedings of the 2011 44th Hawaii International Conference on System Sciences, Kauai, HI, USA, 4-7 January 2011; pp. 1-8.

129. Sivrikaya, B.T.; Kaya, A.; Dursun, M.; Çebi, F. Fuzzy AHP—Goal Programming Approach For a Supplier Selection Problem. Res. Logist. Prod. 2015, 5, 271-285.

130. Roshandel, J.; Miri-Nargesi, S.S.; Hatami-Shirkouhi, L. Evaluating and selecting the supplier in detergent production industry using hierarchical fuzzy TOPSIS. Appl. Math. Model. 2013, 37, 10170-10181. [CrossRef]

131. Bas, E. The integrated framework for analysis of electricity supply chain using an integrated SWOT-fuzzy TOPSIS methodology combined with AHP: The case of Turkey. Int. J. Electr. Power Energy Syst. 2013, 44, 897-907. [CrossRef]

132. Wang, C.H. Using quality function deployment to conduct vendor assessment and supplier recommendation for business-intelligence systems. Comput. Ind. Eng. 2015, 84, 24-31. [CrossRef]

133. Hsu, C.H.; Wang, F.K.; Tzeng, G.H. The best vendor selection for conducting the recycled material based on a hybrid MCDM model combining DANP with VIKOR. Resour. Conserv. Recycl. 2012, 66, 95-111. [CrossRef]

134. Zou, Z.; Tseng, T.L.; Sohn, H.; Song, G.; Gutierrez, R. A rough set based approach to distributor selection in supply chain management. Expert Syst. Appl. 2011, 38, 106-115. [CrossRef]

135. Vinodh, S.; Anesh Ramiya, R.; Gautham, S.G. Application of fuzzy analytic network process for supplier selection in a manufacturing organisation. Expert Syst. Appl. 2011, 38, 272-280. [CrossRef]

136. Shemshadi, A.; Shirazi, H.; Toreihi, M.; Tarokh, M.J. A fuzzy VIKOR method for supplier selection based on entropy measure for objective weighting. Expert Syst. Appl. 2011, 38, 12160-12167. [CrossRef]

137. Yu, C.; Wong, T.N. An agent-based negotiation model for supplier selection of multiple products with synergy effect. Expert Syst. Appl. 2015, 42, 223-237. [CrossRef]

138. Guarnieri, P.; Sobreiro, V.A.; Nagano, M.S.; Marques Serrano, A.L. The challenge of selecting and evaluating third-party reverse logistics providers in a multicriteria perspective: A Brazilian case. J. Clean. Prod. 2015, 96, 209-219. [CrossRef]

139. Bruno, G.; Esposito, E.; Genovese, A.; Passaro, R. AHP-based approaches for supplier evaluation: Problems and perspectives. J. Purch. Supply Manag. 2012, 18, 159-172. [CrossRef]

140. Dargi, A.; Anjomshoae, A.; Galankashi, M.R.; Memari, A.; Tap, M.B.M. Supplier Selection: A Fuzzy-ANP Approach. Procedia Comput. Sci. 2014, 31, 691-700. [CrossRef]

141. Tyagi, M.; Kumar, P.; Kumar, D. A Hybrid Approach using AHP-TOPSIS for Analyzing e-SCM Performance. Procedia Eng. 2014, 97, 2195-2203. [CrossRef]

142. Kannan, D.; Govindan, K.; Rajendran, S. Fuzzy Axiomatic Design approach based green supplier selection: A case study from Singapore. J. Clean. Prod. 2015, 96, 194-208. [CrossRef]

143. Jharkharia, S.; Shankar, R. Selection of logistics service provider: An analytic network process (ANP) approach. Omega 2007, 35, 274-289. [CrossRef]

144. van Eck, N.J.; Waltman, L. Software survey: VOSviewer, a computer program for bibliometric mapping. Scientometrics 2010, 84, 523-538. [CrossRef] 
145. van Eck, N.J.; Waltman, L. VOS: A New Method for Visualizing Similarities Between Objects. In Advances in Data Analysis; Decker, R., Lenz, H.J., Eds.; Springer: Berlin/Heidelberg, Germany, 2007; pp. 299-306. ISBN 978-3-540-70980-0.

146. Peters, H.P.F.; van Raan, A.F.J. Co-word-based science maps of chemical engineering. Part I: Representations by direct multidimensional scaling. Res. Policy 1993, 22, 23-45. [CrossRef]

147. Rip, A.; Courtial, J.P. Co-word maps of biotechnology: An example of cognitive scientometrics. Scientometrics 1984, 6, 381-400. [CrossRef]

148. Konys, A.; Watróbski, J.; Różewski, P. Approach to Practical Ontology Design for Supporting COTS Component Selection Processes. In Intelligent Information and Database Systems; Selamat, A., Nguyen, N.T., Haron, H., Eds.; Springer: Berlin/Heidelberg, Germany, 2013; Volume 7803, pp. 245-255. ISBN 978-3-642-36542-3.

149. Guarino, N. Formal ontology, conceptual analysis and knowledge representation. Int. J. Hum. Comput. Stud. 1995, 43, 625-640. [CrossRef]

150. Gruber, T.R. A translation approach to portable ontology specifications. Knowl. Acquis. 1993, 5, $199-220$. [CrossRef]

151. Sure, Y.; Staab, S.; Studer, R. On-To-Knowledge Methodology (OTKM). In Handbook on Ontologies; Staab, S., Studer, R., Eds.; Springer: Berlin/Heidelberg, Germany, 2004; pp. 117-132. ISBN 978-3-662-11957-0.

152. Corcho, O.; Fernández-López, M.; Gómez-Pérez, A.; López-Cima, A. Building Legal Ontologies with METHONTOLOGY and WebODE. In Law and the Semantic Web; Benjamins, V.R., Casanovas, P., Breuker, J., Gangemi, A., Eds.; Springer: Berlin/Heidelberg, Germany, 2005; Volume 3369, pp. 142-157. ISBN 978-3-540-25063-0.

153. Musen, M.A. The protégé project: A look back and a look forward. AI Matters 2015, 1, 4-12. [CrossRef]

(C) 2019 by the author. Licensee MDPI, Basel, Switzerland. This article is an open access article distributed under the terms and conditions of the Creative Commons Attribution (CC BY) license (http://creativecommons.org/licenses/by/4.0/). 